\title{
ENTRE EL CONFLICTO Y LA COOPERACIÓN: LA CIUDAD CASTELLANA Y LOS CORREGIDORES, PRAXIS DE UNA RELACIÓN POLÍTICA HASTA LA MONARQUÍA ISABELINA*
}

\section{Between Conflict and Cooperation: Castilian Cities and Corregidores, the Praxis of a Political Relationship up to the Catbolic Monarchs}

José Antonio JARA FUENTE

Universidad de Castilla-La Mancha

Correo-e: JoseAntonio.Jara@uclm.es

RESUMEN: En el marco del proceso de centralización política emprendida por la dinastía Trastámara, especialmente a lo largo del siglo xv, la institución del corregimiento ha sido tradicionalmente considerada como uno de los más perfectos instrumentos que ilustran las etapas e intensidad con la que se avanzó en el desarrollo de ese objetivo. La imposición de corregimientos a las ciudades ha sido considerada por la historiografía como una suerte de derrota del mundo urbano, de especial debilidad de aquellos concejos más proclives a someterse a la injerencia de estos oficiales regios. Sin embargo, nos consta que las ciudades fueron capaces de enfrentarse a la imposición de estos agentes con cierto grado de éxito. No solo lograron, en determinadas circunstancias, evitar el nombramiento o el recibimiento del oficial sino que, en muchos casos, la recepción del corregidor constituyó la fase final de un proceso de negociación llevado adelante no necesariamente con el monarca sino singularmente con el agente regio. Una negociación

* Este trabajo ha sido realizado en el seno del proyecto de investigación Ciudad y nobleza en la Castilla de la Baja Edad Media: la (re)construcción de un marco de relaciones competitivo, Ministerio de Economía y Competitividad, Gobierno de España (HAR2013-42787-P). 
que lubricó la relación así generada entre ambas partes, rediseñándola en términos de colaboración política. El objeto de este estudio es precisamente poner de manifiesto el modo en el que se percibe a estos agentes regios en el contexto de esos procesos de relación, conflictiva en unas ocasiones, negociada en otras, y la capacidad de acción política autónoma que cabe atribuir a las ciudades en ese marco de política centralizadora. El terminus ad quem del estudio viene constituido por la inauguración de la monarquía isabelina, que supone, ya desde las Cortes de Toledo de 1480, el inicio de una fase distinta en el proceso de consolidación de la institución del corregimiento.

Palabras clave: Corona de Castilla; siglo xv; ciudades; corregidores; conflicto y cooperación.

ABSTRACT: In the frame of the process of political centralization undertook by the Trastámaras, in special during the fifteenth century, scholars have traditionally regarded the institution of the «corregimiento" (the «corregidores»-keepers of the town- were royal agents appointed to oversee the government and, in general, administration of royal cities and towns) as one of the most perfect instruments highlighting the stages and intensity with which that aim was achieved. Historians have considered the imposition of the «corregimientos» over the towns as a defeat of the urban world, as a trait of weakness on the part of those towns especially predisposed to subject themselves to the political interference represented by these royal officials. Nevertheless, we know that towns were able to face the imposition of these agents with some degree of success. In some circumstances, they not only managed to avoid the appointment or even the effective inauguration into office of these officials but, in many cases, the «corregidor» inauguration constituted the last phase in a process of negotiation not necessarily conducted with the monarch but singularly with the royal agent. These negotiations helped to lubricate the relationship thus generated between both parties, redefining it in terms of political cooperation. The aim of this paper is to demonstrate the way in which these royal agents were perceived in the frame of those processes of relationship-sometimes endowed with a conflictive nature, sometimes showing negotiating traits-, and the ability showed by cities and towns to develop an autonomous political action in the frame of the more global process of political centralization. The terminus ad quem of this paper is the inauguration of the Elizabethan monarchy, since, from the Parliament of Toledo of 1480, 
JOSÉ ANTONIO JARA FUENTE

ENTRE EL CONFLICTO Y LA COOPERACIÓN: LA CIUDAD CASTELLANA Y LOS CORREGIDORES, PRAXIS DE UNA RELACIÓN POLÍTICA HASTA LA MONARQUÍA ISABELINA

it implies the beginning of a different phase in the process of institutional consolidation of the «corregimiento».

Key words: Crown of Castile; Fifteenth Century; Towns; Keepers of the Town; Conflict and Cooperation.

\section{INTRODUCCIÓN}

El 9 de octubre de 1420, comparecía ante el concejo de Cuenca Juan Sánchez de Peralta, bachiller y alcalde de corte, requería a la ciudad su recibimiento como juez y corregidor y, sin esperar a ver cumplida la formalidad del recibimiento, ordenaba la suspensión de los oficios de justicia, alcaldes y alguacil:

E luego el dicho Diego Furtado tomó la dicha carta del dicho sennor rey en la mano e posóla en somo de su cabeça e dixo que la obedesçía e obedesçió con [humilde] e deuida reuerençia, commo a carta de su rey e sennor natural [...] e que en rasón del conplimiento de ella, que el dicho conçejo aurán su acuerdo e darán su respuesta, aquella que cumple a seruiçio del dicho sennor rey e a pro común de la dicha çibdat e de su tierra [...] E luego los dichos Gomes Garçía e Lope Sánchez e Françisco Martínez, regidores, e Garçía Áluares de Salas e Diego Gutierres de Camargo e Sancho Sánchez de Arcas, alcaldes, e Pero Nunnes, alguaçil, dixieron que obedesçían e obedesçieron la dicha carta del dicho sennor rey, segund que de suso obedeçían ésta, e que en rasón del conplimiento de ella, que aurán su acuerdo e que son prestos de faser todo lo que cumple a seruiçio del dicho sennor rey e a pro e bien de la dicha çibdat e de su tierra ${ }^{1}$.

Si bien el contexto político local en el que se produce el nombramiento regio de Sánchez de Peralta es singular, y sobre él volveré más adelante, la actitud mostrada por el guarda mayor de Cuenca, Diego Hurtado de Mendoza, y por el concejo, no lo es. Representa un modelo de gestión, en su fase inicial, del modo en el que la ciudad encara sus relaciones con los agentes externos al concejo, y especialmente con los agentes regios, singularmente con los corregidores -objeto de este trabajo. Aunque a lo largo del estudio se examinará estas cuestiones, conviene tener presente desde un primer momento el marco en el que se gestiona el actuar de la ciudad. Un marco que el texto citado más arriba ayuda a explicitar: en primer lugar, la unidad o, cuando menos, la aparente unidad de acción que anima al concejo en su respuesta a la autoridad central y sus agentes, aquí ejemplificada

1. Archivo Municipal de Cuenca [en adelante AMC], Libros de Actas [en adelante LLAA], legajo [en adelante leg.] 185, expediente [en adelante exp.] 6, folios [en adelante fols.] 21r y 23v-25r. 
por el cierre de filas actuado por el guarda mayor, regidores, alcaldes y alguacil ordinarios. En segundo lugar, la autonomía, o al menos la aparente autonomía política que subyace a ese actuar. Un actuar que enfrenta la relación con estos, y otros, agentes regios sobre la base del principio jurídico y la praxis política del obedesçían e obedesçieron [e] en rasón del conplimiento [...] aurán su acuerdo, es decir sobre la afirmación de un marco jurídico-político que permitía a la ciudad enfatizar y, en su caso, reclamar: primero, el respeto formal expresado a la autoridad regia; segundo, el derecho que corresponde a la ciudad, y la exigencia de que este sea respetado, de examinar la legalidad del acto, decisión, o disposición cuyo cumplimiento se les exige; y tercero, el ejercicio de sus derechos y privilegios en materia de deliberación y toma de acuerdos ${ }^{2}$. Por último, en tercer lugar, la manifestación hecha por el concejo ese 9 de octubre de 1420 se justificaba sobre la base del fundamento legal e ideológico que proporciona cobertura a la acción política urbana, es decir el servicio al rey y a la ciudad; nociones que, por paradójico que parezca, permiten deservir al rey al tiempo que se le sirve, es decir no cumplir con un mandato regio por considerar que lo contrario iría en deservicio del monarca (y de la ciudad, desde luego).

¿Hasta qué punto ese principio jurídico y praxis política no encerraban sino un mero formalismo que, salvada la observación de los requisitos procedimentales oportunos, conducía inevitablemente a la sanción positiva del mandato regio? El caso de Juan Sánchez de Peralta resulta especialmente atractivo porque se trata del nombramiento de un corregidor, oficio que sublima el nivel de injerencia que todo agente externo supone, o puede suponer, en el ámbito de la autonomía política urbana. En este caso, la formulación por el concejo de Cuenca

2. Poco más de cuarenta años más adelante, el 2 de octubre de 1463, en Segovia, Enrique IV escribiría al concejo de Cuenca confirmando esta facultad de examen de las disposiciones regias por parte de las ciudades, al reiterarle lo dispuesto en las pasadas Cortes de Toledo de 1462 sobre que cuando se dicte una carta contra ley o fuero o derecho, que la tal carta sea obedesçida $e$ non conplida (AMC, LLAA, leg. 196, exp. 1, fols. 29v-31v). En esta ocasión, el monarca no se estaba refiriendo solo a la petición 7 de las Cortes de Toledo de 1462, que simplemente referían la obediencia y cumplimiento/incumplimiento al correcto registro legal del documento de que se tratara (Cortes de Toledo de 1462, petición 7, en Cortes de los antiguos reinos de León y de Castilla, Madrid, 1866, vol. III), sino a una amplia tradición legal que se retrotrae al Espéculo (IV, 6, 8) y las Partidas (III, 18, 34), y que, al margen de peticiones previas a la monarquía, comienza a encontrar su plasmación en Cortes, en las de Madrid de 1329 (petición 33) y en las de Valladolid de 1351 (petición 16). Sobre el particular, véanse Bermejo Cabrero, J. L.: «La idea medieval de contrafuero en León y Castilla», Revista de Estudios Políticos, 187, 1973, pp. 299-306; y GonzÁlez Alonso, B.: «La fórmula «Obedézcase pero no se cumpla en el Derecho castellano de la Baja Edad Media», Anuario de Historia del Derecho Español, 50, 1980, pp. 469-488. 
del principio de evaluación de la adecuación de la conducta (y disposiciones) regia(s) a los principios políticos y jurídicos en juego, ilustra la realidad y efectividad de la capacidad de gestión independiente de la ciudad. Esa autonomía, esa capacidad de posicionamiento político crítico frente al rey y sus agentes constituyó un rasgo no solo teórico sino en numerosas ocasiones práctico del urbanismo castellano a lo largo del siglo xv. Aunque las ciudades no fueron en general capaces de cortocircuitar en origen el nombramiento de estos oficiales, y desde luego de los corregidores - pues, entre otras razones, se trataba de una fase esencialmente ajena a ellas y alejada de sus espacios de toma de decisiones, al centrarse en la corte, en la persona del monarca y sus asesores; sí fueron capaces de oponerse efectivamente al recibimiento de corregidores y otros oficiales regios, provocando, en la mayor parte de ocasiones, la negociación con la monarquía y, en no pocos casos, la retirada del nombramiento y aun de la intención de designar a un nuevo oficial. De esta manera, el proceso de centralización política que se persigue bajo la dinastía Trastámara y especialmente a lo largo del siglo xv, y en el que la paulatina implantación de este colectivo de oficiales en las ciudades constituye una de sus herramientas más visibles, no se verificó sobre un espacio, el urbano, ayuno de capacidad de acción y reacción ${ }^{3}$. De hecho, al menos hasta la pacificación del reino en 1480, las ciudades manifestaron una percepción de la institución del corregimiento aparentemente contradictoria, en la medida en que tanto mostraron una, en ocasiones feroz, capacidad de oposición como una no

3. Para un examen general de los corregimientos en la Castilla medieval (desde perspectivas histórico-institucionales y jurídicas), siguen constituyendo obras de referencia los estudios de GonzÁlez Alonso, B.: El corregidor castellano (1348-1808). Madrid, 1970 y, del mismo autor «Monarquía, ciudad, corregidores (Castilla, 1480-1523)», en BELENGUER CEBRiá, E. (coord.): De la unión de coronas al Imperio de Carlos V, congreso internacional, Barcelona, 2000, 3 vols., Madrid, 2001, I, pp. 281-298; Bermúdez Aznar, A.: El corregidor en Castilla durante la Baja Edad Media (1348-1474). Murcia, 1974, y del mismo autor, «El asistente real en los concejos castellanos bajomedievales», en Actas del II Symposium de Historia de la Administración. Madrid, 1971, pp. 225-251; Bermejo CABRERo, J. L.: «Mayoría de justicia del rey y jurisdicciones señoriales en la Baja Edad Media castellana», en Actas de las I Jornadas de Metodología Aplicada de las Ciencias Históricas. II. Historia Medieval. Santiago de Compostela, 1975, pp. 207-215; y Lunenfeld, M.: Keepers of the City. The Corregidores of Isabella I of Castile (1474-1504). Cambridge (Mass.), 1987. Desde una perspectiva más centrada en el funcionamiento efectivo de los aparatos de poder (y, desde luego, justicia urbanos), los procesos de coordinación (y conflicto) de las diversas autoridades participantes (local, central y/o señorial), así como la ideología subyacente al modelo urbano de justicia, resultan imprescindibles los trabajos de Monsalvo Antón, J. M.: «El reclutamiento del personal político concejil. La designación de corregidores, alcaldes y alguaciles en un concejo del siglo XV", Studia Historica. Historia Medieval, 5, 1987, pp. 173-195; y Bonachía Hernando, J. A.: «La justicia en los municipios castellanos bajomedievales», Edad Media. Revista de Historia, 1, 1998, pp. 145-182. 
menor capacidad de colaboración, marcada incluso por las peticiones dirigidas al monarca para que designara corregidor. Además, es muy posible que esa posición política ambivalente frente al corregidor se prolongara hasta la década de 1490, al menos en algunos espacios urbanos marcados por una mayor presión de la nobleza territorial y una mayor necesidad de oficiales regios capaces de hacer retornar a ciudades y villas las áreas ilegalmente ocupadas por sus vecinos nobles, y de protegerlas de la reacción de estos ${ }^{4}$; una necesidad de mediación activa que pudo extenderse también a la propia organización de la estructura urbana de poder ${ }^{5}$.

En cualquier caso, las ciudades mostraron una capacidad de diálogo con la institución del corregimiento que fue más allá de la simple aceptación de la imposición del centralismo monárquico o la no menos simple y directa oposición a su recibimiento. Lo que llama especialmente la atención en este largo proceso de institucionalización de la figura en los marcos urbanos, es la capacidad de comunicación mostrada por ambas partes, las agencias urbanas de poder y los corregidores y sus oficiales.

No obstante, aunque son ya numerosos los trabajos dedicados a examinar la presencia de los corregidores y sus oficiales en los concejos castellanos, los problemas planteados por la ausencia de fuentes seriadas (para muchas ciudades y villas no se comienza a disponer de estas hasta más allá de mediados o incluso fines del siglo xv), han reconducido en general estos estudios a un análisis global de las políticas de corregimiento en cada concejo; a la presentación de listados de oficiales, más o menos extensos en contenido y no pocas veces circunscritos a

4. Esta es mi apreciación para el caso de Cuenca. En este sentido, en un reciente trabajo, Sánchez Benito ha examinado la interposición de los corregidores en los conflictos locales protagonizados por la nobleza territorial en este área. Por su parte, Quintanilla Raso plantea un horizonte radicalmente opuesto, afirmando la ineficacia de los corregidores, que liga, en general, a su connivencia con los linajes nobles implicados en esas usurpaciones. Vid. Sánchez Benito, J. M.: «Nobleza territorial y política ciudadana en el siglo xv (los concejos del área del Tajo)», Espacio, Tiempo y Forma. Serie III. Historia Medieval, 27, 2014, pp. 463-502; y Quintanilla Raso, M. C.: «Estructuras y relaciones de poder en la tierra de Cuenca a fines de la Edad Media», en La Península Ibérica en la Era de los Descubrimientos (1391-1492), actas de las III Jornadas Hispano-Portuguesas de Historia Medieval. 2 vols., Sevilla, 1991, 1997, I, pp. 707-736.

5. Es lo que sucede, por ejemplo, en Lorca, donde el corregidor mosén Juan Cabrero realiza una profunda modificación de la planta de oficios, afectando al número de regidurías y a los procedimientos de cooptación de nuevos regidores y demás oficiales (que deja en manos de los regidores en activo, motivo el que muy probablemente su gestión no recibió la oposición del concejo). Vid. Robledo del Prado, M. L.: Formación y evolución de una oligarquía local: Los regidores de Lorca, tesis doctoral defendida en el Departamento de Historia Moderna de la Universidad Complutense de Madrid, enero de 1995, edición facsímil, Madrid, 2002, p. 24. 
JOSÉ ANTONIO JARA FUENTE

ENTRE EL CONFLICTO Y LA COOPERACIÓN: LA CIUDAD CASTELLANA Y LOS CORREGIDORES, PRAXIS DE UNA RELACIÓN POLÍTICA HASTA LA MONARQUÍA ISABELINA

los corregidores y, en el mejor de los casos, a sus tenientes, haciendo abstracción de alcaldes y alguaciles mayores; y a exámenes más detenidos pero centrados en el período mejor documentado, la monarquía isabelina ${ }^{6}$. Evidentemente, en ese marco de análisis la percepción que las ciudades tuvieron de los corregidores y sus oficiales antes de 1480 queda, en muchos casos, reducida a planteamientos de carácter general o a la extrapolación, convenientemente modificada, de lo que sabemos para el período posterior a 1480. En este estudio, a partir del examen de un concejo que proporciona un aporte documental significativo, el de Cuenca, y del cotejo de lo que sucede en un contexto urbano más amplio, se pretende trascender

6. Merece tenerse presente los estudios de Cabrera Sánchez, M.: «Los corregidores de Córdoba en el siglo xv», Meridies. Revista de Historia Medieval, 2, 1995, pp. 95-108; RuIz Povedano, J. M.: «Poder, oligarquía y parcialidades en Alcalá la Real: el asesinato del corregidor Bartolomé de Santa Cruz (1492)», Historia. Instituciones. Documentos, 29, 2002, pp. 397-427; Franco Silva, A. y Cruz Mariño, R.: «Juan Pacheco, privado de Enrique IV, y el oficio de corregidor de Jerez de La Frontera», En la España Medieval, 35, 2012, pp. 285-316; también con carácter general para el ámbito andaluz, RUFO YSERN, P.: «Extensión del régimen de corregidores en Andalucía en los primeros años del reinado de los Reyes Católicos», en Las ciudades andaluzas (siglos XIII-XVI), actas del VI Coloquio Internacional de Historia Medieval de Andalucía. Málaga, 1991, pp. 55-75; López Gómez, Ó.: «Claves del sistema de pacificación ciudadana desarrollado por los Reyes Católicos en Toledo (1475-1485)», En la España Medieval, 27, 2004, pp. 165-193; y así mismo para Toledo, Palencia Herrejón, J. R.: Ciudad y oligarquía de Toledo a fines del medievo (1422-1522), tesis doctoral defendida en el Departamento de Historia Medieval de la Universidad Complutense de Madrid, 1999, especialmente el apartado 2.5. «La regularización del control regio en Toledo: Corregiduría y corregidores», pp. 275-314; López Villalba, J. M.: «El concejo imparte justicia: cotos de los oficiales locales a mediados del siglo xv», Espacio, Tiempo y Forma. Serie III. Historia Medieval, 22, 2009, pp. 153-184; e igualmente para Guadalajara, GARcía LóPEz, A.: «El corregidor y el conflicto ciudad-lugar en el Reino de Castilla (ss. Xvi-XviI)», en Bernardo Ares, J. M. y González Beltrán, J. M. (coords.): La administración municipal en la Edad Moderna, actas de la V reunión científica de la Asociación Española de Historia Moderna. 2 vols. Cádiz, II, 1999, pp. 529-540; CuARTAS Rivero, M.: «Los corregidores de Asturias en la época de los Reyes Católicos (1474-1504)», Asturiensia Medievalia, 2, 1975, pp. 259-278; Martínez Carrillo, M. L.: «La implantación de los corregidores en el concejo murciano (1394-1402)», Miscelánea Medieval Murciana, 10, 1983, pp. 167-196; y también para Murcia, Jiménez Alcázar, J. F.: «Corregidores y poder municipal: Lorca, 1475-1516», en Pradells Nadal, J. y Hinojosa Montalvo, J. R. (coords.): 1490: en el umbral de la modernidad: el Mediterráneo europeo y las ciudades en el tránsito de los siglos XV-XVI. 2 vols., Valencia, 1994, II, pp. 87-96; CoRRAL, J.: «Corregidores y alcaldes de Madrid. Estado de la cuestión», Anales del Instituto de Estudios Madrileños, 36, 1996, pp. 187-204; YвÁÑEz Worboys, P.: «Los corregidores malagueños (1517-1556)», en Actas de la V reunión científica de la Asociación Española de Historia Moderna. 2 vols., Cádiz, 1998-1999, II, pp. 179-190; y NARganes QuiJano, F.: «Acerca de los primeros corregidores en Palencia (ss. XV-Xvi)», Publicaciones de la Institución Tello Téllez de Meneses, 64, 1993, pp. 597-610. A lo largo de las siguientes páginas se irán citando otros textos de referencia, no incluidos en esta bibliografía. 
esas visiones más generales, poniendo de manifiesto la relación existente entre ciudades y corregidores en el período pre-isabelino.

\section{LA OPOSICIÓN DE LAS CIUDADES A LA PRESENCIA DE LOS CORREGIDORES}

Aunque en este trabajo me centraré en la relación ciudades-corregidores, habría que tener presente que estos no fueron los únicos agentes regios cuya presencia en el marco urbano podía verse percibida de una manera similar. El corregidor, y por extensión sus oficiales, constituyen la máxima expresión de la injerencia regia en la ciudad, no solo porque su presencia suspende los oficios de justicia, sino porque implican una participación en el entero proceso de toma de decisiones del concejo urbano (hay que tener en cuenta que la presencia de otros agentes, como algunos pesquisidores, también conlleva esa suspensión, pero no un nivel de injerencia similar, pues su capacidad funcional viene sensiblemente limitada en su nombramiento). Pero hay otros agentes que también se hacen presentes en el ámbito urbano. Acabo de citar a los pesquisidores, y a ellos habría que incorporar, en ese siglo Xv entreverado de guerras civiles, a una amplia nómina de oficiales dotados, en algunos casos, de específicas funciones militares, como asistentes, gobernadores y capitanes, entre otros, algunos de los cuales, como asistentes y gobernadores, no dejaron de ser sino fórmulas de inserción de oficiales regios con similares (aunque nunca idénticos) poderes a los de los corregidores, en contextos en los que la presencia de estos resultó fuertemente discutida y objeto de una oposición exitosa ${ }^{7}$. Es cierto que, asumiendo esa injerencia como un rasgo esencial de la naturaleza de estos oficios, el corregimiento supuso la paulatina consolidación de la proyección de la autoridad real sobre el mundo urbano castellano. Pero, a la hora de examinar no solo la lógica de la presencia del oficio en las ciudades, sino de su éxito institucional a largo plazo, habría que tener en cuenta otros factores concurrentes que ayudarían a explicar por qué estos oficiales no fueron discutidos en todos los casos e incluso, allí donde y cuando fueron objeto de oposición, su percepción no resultó siempre necesaria y enteramente negativa ${ }^{8}$.

7. Sobre otros agentes regios, como los asistentes, $y$ algunos dotados de concretas funciones militares, como los gobernadores, véanse BERmúdez AznAR, El corregidor en Castilla..., op. cit., p. 97-117 y los mapas en pp. 66-69, ilustrando la presencia de asistentes y corregidores en Castilla durante los reinados de Juan II y Enrique IV; del mismo autor, «El asistente real...», op. cit., pp. 225-251; y LUNENFELD, op. cit., pp. 20-23.

8. Este es el argumento elaborado también por Guerrero Navarrete, para quien el éxito de la institucionalización de la figura del corregidor no se debió solo a la presión regia o a la debilidad urbana, sino a cierto nivel de complicidad por parte del mundo urbano y especialmente de sus elites regimentales, cuya posición de predominio en sus respectivos marcos urbanos no solo no 

PRAXIS DE UNA RELACIÓN POLÍTICA HASTA LA MONARQUÍA ISABELINA

Es así que estas presencias se justifican por esa referencia, que se hace al inicio de este artículo, al sermiçio del dicho sennor rey e a pro e bien de la dicha çibdat $e$ de su tierra. Un llamamiento especialmente sincero en los casos en los que ha sido el propio concejo el que ha reclamado la intervención del agente externo, como sucede en noviembre de 1417, cuando Cuenca solicita a don Enrique de Villena, señor de Torralba y pariente de Juan II, hacer pesquisa en la ciudad por los enfrentamientos, violentos, que protagonizaban los dos grandes bandos nobles presentes en la urbe, los Hurtado de Mendoza, señores de Cañete, y los Vázquez de Acuña, señores de Buendía9. El 19 de octubre, en respuesta a la petición de la ciudad, don Enrique acordaba hacer inquisición y pesquisa, cuyas conclusiones ratificaba el concejo dos días después, el 21 de octubre. Como quiera que la pesquisa en sí no había traído la paz a Cuenca, concluyendo los conflictos que enfrentaban a Lope Vázquez de Acuña y a Diego Hurtado de Mendoza, y habiendo mostrado el señor de Torralba su intención de abandonar la ciudad, el 2 de noviembre el concejo acordaba solicitarle que permaneciera en la urbe y que concluyera con la ejecución de las medidas adoptadas para protegerla de los dos linajes nobles, por ser ello en servicio del rey e pro de la dicha çibdat e de los que en ella biuen. Finalmente, el 3 de noviembre el concejo ratificaba una vez más las medidas propuestas e implementadas por don Enrique ${ }^{10}$. Ni la pesquisa ni las medidas de defensa adoptadas con posterioridad solucionaron el contencioso pero -en coordinación con, o incluso en simple yuxtaposición a, otras accionessí supusieron un importante instrumento de pacificación, cuyo mayor éxito se encontró en la activa y positiva comunicación entre concejo y pesquisidor. En este sentido, convendría tener presente varios extremos. Primero, que la presencia de don Enrique había sido solicitada por Cuenca, no impuesta a la ciudad; en este contexto, resulta tanto más significativo el hecho de que el concejo no considerara necesario utilizar el mecanismo intermediador de la corona para tratar con el señor de Torralba, dirigiéndose directamente a él para solicitar sus servicios; aunque, evidentemente, sí consideró oportuno enmarcar el conjunto de estas acciones en la cobertura legitimadora del servicio al rey (y a la ciudad, sin duda). Segundo,

contestaba los corregimientos, sino que la presencia de los corregidores contribuía a consolidar. Vid. Guerrero Navarrete, Y.: «Orden público y corregidor en Burgos (siglo xv)», Anales de la Universidad de Alicante. Historia Medieval, 13, 2000-2002, pp. 59-102.

9. Sobre las implicaciones de este conflicto y la participación activa que cupo al concejo de Cuenca en su resolución, véase JaRA Fuente, J. A.: «Consciencia, alteridad y percepción: la construcción de la identidad en la Castilla urbana del siglo XV», en Jara Fuente, J. A., Martin, G. y Alfonso Antón, I. (coords.): Construir la identidad en la Edad Media. Poder y memoria en la Castilla de los siglos VII a XV. Cuenca, 2010, pp. 221-250.

10. AMC, LLAA, leg. 185, exp. 1, fols. 28r-29v, 10v-11r y 26v-27r. 
que don Enrique procuró en todo momento cobijar su actuación bajo el paraguas legitimador de la colaboración con e incluso supervisión por parte del concejo. Cuenca pudo así sentirse actor, parte activa de las gestiones realizadas por aquel: de este modo, como ya sabemos, el 19 de octubre, don Enrique proponía al concejo hacer la pesquisa en colaboración con García Álvarez de Albornoz, guarda mayor de la ciudad, y los alcaldes ordinarios, con el fin de evitar recelos y asegurar que aquella se realizaba sin bandería (el concejo lo aprobó); el 21 de octubre, la ciudad ratificaba la pesquisa, lo que suponía no solo conferirle plena validez, sino afirmar el papel del concejo como titular último de esa potestad (así, la pesquisa no se realizaba por una agencia externa a la ciudad y fuera de su control, sino por la propia agencia urbana, delegando, eso sí, en un agente externo «a su servicio»); el 2 de noviembre, el concejo encomendaba al guarda mayor, a los regidores, los alcaldes ordinarios y otros diez hombres buenos, acudir ante don Enrique para solicitarle que continuara en sus funciones (la ampliación del personal seleccionado para realizar la gestión a una representación de hombres buenos -seleccionada por los propios regidores, desde luego- perseguía dotar de legitimidad colectiva no solo a la solicitud de permanencia en la ciudad de don Enrique de Villena, sino, por extensión, a cuanto aquel había realizado hasta el momento y se le rogaba que continuara ejecutando); y, finalmente, el 3 de diciembre, la ciudad ratificaba todo lo hecho por el señor de Torralba durante el último mes, señalaba que ello ya había sido sometido a juramento en algunas cuadrillas, y ordenaba al alcalde ordinario García Sánchez Dones que lo sometiera a juramento en aquellas donde aún no se había procedido a ello (nuevamente, estos juramentos representaban la fuerza del compromiso de la ciudad, entendida como la comunidad de vecinos y no solo como los órganos ejecutivos institucionales, con las acciones ejecutadas con motivo de la pesquisa). El papel protagonista, incluso rector, asumido por el concejo en esta ocasión, explica la sencillez con la que se acogieron las medidas propuestas por el de Villena (lamentablemente, la documentación relativa a estas no se ha conservado). No se trató solo de que el concejo solicitara la intervención de un tercero y, consiguientemente, asumiera el nombramiento y la gestión aparejada; sino de que don Enrique de Villena procurara en todo momento hacer participar a la ciudad en su actuación, aceptando él también la superior función de validación del concejo. Es en este proceso de comunicación política donde residió el éxito de su gestión. Y es en similares procesos de comunicación política donde residió el éxito de otros agentes, oficiales designados por el monarca -con el acuerdo o no del concejo interesado- para intervenir en la política urbana.

Una intervención cuya justificación por parte del monarca se construye, en la generalidad de ocasiones, sobre la base de la propia demanda hecha por el concejo. Una solicitud, la urbana, en algunos casos más teórica que real y, por lo 
tanto, que debemos entender dotada de lógica discursiva (la reclamación por el monarca del plus de legitimidad que proporcionaba a su decisión el contar con la previa aprobación de la ciudad), pero que en todos los casos se reduce, como no podía ser de otra manera, a la necesidad de restaurar el servicio al rey y a la ciudad, el procomún urbano; y se vincula, especialmente en las primeras décadas del siglo xv, a la política banderiza experimentada y sufrida por las ciudades castellanas. En este sentido, Guerrero Navarrete ha resaltado la vinculación de la presencia del corregidor a los problemas planteados por esas políticas banderizas y la necesidad de restauración del orden público en las ciudades como superior valor de convivencia y de preservación del orden político local; un objetivo cuya funcionalidad de control político y, más en general, de control del poder en las ciudades compartirían las elites urbanas, lo que las colocaría en una relación contradictoria con la designación y mandato del corregidor, cuya presencia constituía una clara denuncia de la incapacidad de esas elites para establecer o restablecer el orden urbano (especialmente cuando ellas mismas resultaban responsables de los conflictos políticos), y cuyo éxito -el del corregidor- suponía no solo el triunfo de la agencia monárquica, sino el afianzamiento de las respectivas posiciones de poder de dichas elites ${ }^{11}$.

11. Guerrero Navarrete, Y.: «La política de nombramiento de corregidores en el siglo xv: entre la estrategia regia y la oposición ciudadana», Anales de la Universidad de Alicante. Historia Medieval, 10, 1994-1995, pp. 99-124, y op. cit., pp. 59-102. Respecto de la vinculación de los nombramientos de corregidores a la pacificación de la vida política urbana, véanse DiAGO HERnANDO, M.: «El papel de los corregidores en los conflictos políticos en las ciudades castellanas a comienzos del siglo Xvi», En la España Medieval, 27, 2004, pp. 195-223; y Martínez Peñas, L. y FERNÁNDEZ RodRíGUEz, M.: «La respuesta regia al desorden urbano: la doble naturaleza de los corregidores», en idem (coords.): Amenazas y orden público: efectos y respuestas, de los Reyes Católicos al Afganistán contemporáneo. Madrid, 2013, pp. 9-27. Y, especialmente para un espacio tan significativo en materia banderiza como el vasco, vid. Dacosta Martínez, A.: «Porque él fasía desafuero. La resistencia estamental al corregidor en la Bizkaia del siglo Xv», en Porres Marijuán, M. ${ }^{a}$ R. (coord.): Poder, resistencia y conflicto en las Provincias Vascas (siglos XV-XVIII). Bilbao, 2001, pp. 37-64; y RitTERSTEIn, R. G. R.: «La oposición a muerte. Bandos vs. corregidores provinciales: los casos de Gonzalo Moro y Juan Martínez de Burgos. La acción de los banderizos en la Baja Edad Media vasca», Fundación para la Historia de España-Argentina. 6, 2002-2003, pp. 109-126. Analizando este tipo de conflictos banderizos y la designación de corregidores ligada a la específica resolución de esos problemas, Asenjo González afirma la importancia del elemento "pacificador» en la función de la institución del corregimiento y su esencial temporalidad -vinculada a la solución del concreto conflicto-, como rasgos específicos de los corregimientos antes de 1480 . Se trata de una aproximación atractiva, que responde a la lógica de algunos de esos nombramientos, especialmente durante la monarquía de Juan II, cuando las acciones banderizas locales se yuxtaponen, en muchos casos, a los conflictos provocados por los infantes de Aragón. Sin embargo, la reiteración de la presencia de estos oficiales en algunos concejos -expresada tanto en la sucesión de nombramientos de corregidor como en la renova- 

PRAXIS DE UNA RELACIÓN POLÍTICA HASTA LA MONARQUÍA ISABELINA

Conexión que ilustra, muy gráficamente, la carta que Juan II dirige a Cuenca, el 31 de agosto de 1420, notificando el referido nombramiento de Juan Sánchez de Peralta y justificándolo en la denuncia hecha por algunos vecinos, entre ellos por el regidor Ferrand Suárez Gallego, de los muchos bolliçios e escándalos e insultos que se cometían en ciudad y tierra, y de las muertes de omnes e robos e fuerças $e$ furtos e feridas e otros malefiçios enormes e desaguisados, que quedaban impunes por negligencia e impotencia de los alcaldes y por la fuerza de los malhechores y el favor que recibían de algunos caballeros y personas poderosas (en clara referencia a los linajes de la nobleza territorial) ${ }^{12}$. Años después, el 20 de noviembre de 1431, y pocos años más tarde, el 12 de julio de 1434, el monarca se dirigía a la ciudad acudiendo una vez más a los mismos argumentos para justificar el nombramiento de nuevos corregidores ${ }^{13}$.

Que el nombramiento de estos oficiales precisaba de una justificación que fuera más allá de la voluntad regia, se entiende bien si tenemos en cuenta que el objetivo principal perseguido por la ciudad es verse libre de esta imposición y, por lo tanto, una de las respuestas usuales (aunque no procediera en todos los casos) será la oposición al nombramiento. Oposición que se verifica en el ámbito urbano correspondiente, pero también en ese espacio de representación de las ciudades que son las Cortes. Ya en las Cortes de Madrid de 1419 (petición 5), los procuradores habían solicitado al rey que no designara corregidor sin la previa petición de la ciudad interesada (del conjunto de la comunidad, de la mayor parte de ella o según estableciera la costumbre del lugar); y lo mismo reiterarán en las de Ocaña de 1422 (peticiones 2 y 3), sin una respuesta clara del monarca (como en las de 1419, Juan II se remitió a lo dispuesto sobre el particular por Enrique III). No será hasta las Cortes de Palenzuela de 1425

ción en el oficio de algunos de dichos agentes- se encuentra más relacionada con procesos de institucionalización de la agencia regia, que de presencia coyuntural. Vid. AsEnjo González, M.: «Función pacificadora y judicial de los corregidores en las villas y ciudades castellanas, a fines de la Edad Media», Medievalista online. 18, 2015, pp. 1-28, http://www.2.fcsh.unl.pt/ iem/medievalista/MEDIEVALISTA18/gonzalez1804.html.

12. AMC, LLAA, leg. 185, exp. 6, fols. 21-23v.

13. AMC, LLAA, leg. 188, exp. 1, fols. 15r-17r; y leg. 188, exp. 6, fols. 9r-10v. El recurso a la violencia experimentada en la ciudad no solo permitía justificar a la monarquía la introducción de estos agentes externos, sino a las propias autoridades urbanas, la imposición de medidas ordinarias o extraordinarias de "policía», como sucede el 16 de abril de 1434, cuando, ante los insultos e malefiçios [que] fasen asy omes de pie de sennores commo otros omes e vagamundos que non tienen sennores [y los alcaldes y alguacil no les pueden prender porque son muchos y] andan bien armados e juntos de ocho en ocho e de dies en dies e de dose en dose e avn mas, el concejo ordena no solo una veda de armas (recurso ordinario), sino que cada cuadrilla proporcione cuatro hombres para servir con el alguacil (recurso extraordinario). Cfr. AMC, LLAA, leg. 188, exp. 5, fols. 13v-14v. 
(petición 30) cuando, en los casos en los que solo una parte de la comunidad urbana o algún individuo o individuos en particular solicitaran del monarca la designación de un corregidor, Juan II acepte someter su decisión a la realización de un informe, o pesquisa, del que debería dar noticia a la ciudad para que alegara lo que estimara oportuno; procedimiento que depura en las de Zamora de 1432 (petición 11), al vincular la designación de corregidor a la petición previa por parte del concejo afectado (petición que debería hacer el conjunto de la comunidad o la mayor parte de ella) o a su libre decisión (aquí entraría la posibilidad de que terceros le rogaran efectuar el nombramiento), aunque en este último caso sujetaría su decisión final a la elaboración de un informe del que se daría traslado al concejo para su alegación. Este doble mecanismo de 1425 y 1432 demostró su éxito al ser reiterado en las siguientes reuniones de Cortes: en las de Madrid de 1435 (petición 17), Madrigal de 1438 (petición 19), Valladolid de 1442 (petición 10), Burgos de 1453 (petición 21), y Córdoba de 1455 (petición 3) ${ }^{14}$.

Sin embargo, y como vemos que sucede en Cuenca, la oposición al nombramiento de corregidores no solo se escenifica en las Cortes; las propias ciudades constituyen un magnífico teatro sobre el que representar esta oposición política de envergadura. Así sucede en Toledo, en 1421; en Murcia, en 1394, 1443 y 1450, llegando a expulsar al corregidor en 1452; en Burgos, en 1463, donde la oposición al nombramiento del corregidor se vincula no a una oposición política directa, sino al coste económico del oficio, que causaría un gran perjuicio a la ciudad, dadas las pocas rentas que tenía el concejo; en Madrid, en 1465, cuando la villa cierra sus puertas al nuevo corregidor; o en Alcaraz, en 1475, donde la oposición del concejo alcanzó tal intensidad que Isabel I acabaría por revocar el nombramiento (la reina, además, necesitaba la buena disposición de las ciudades y villas del marquesado en su lucha con el marqués de Villena), y como consecuencia de ello y de la oposición generalizada a estos oficiales, se vería obligada a comprometerse en las Cortes de Madrigal de 1476 (petición 28) a no designar corregidor sin el consentimiento del concejo interesado. Poco más de mes y medio después, lo dispuesto en Madrigal encontraba implementación en el ámbito del corregimiento de Guipúzcoa donde, el 18 de junio, Fernando V se sometía a lo planteado en la reclamación presentada por la provincia contra el nombramiento de corregidor, reconociendo que no lo podía nombrar segund las leyes de mis reynos, syn vuestra suplicaçión e petiçión, y confirmando que no lo haría sin contar con la previa petición de la mayor parte de

14. Cortes de los antiguos reinos, t. III, confrontar las peticiones señaladas con sus correspondientes sesiones de Cortes; Bermúdez Aznar, El corregidor en Castilla..., op. cit., pp. 121-123; y LuNENFELD, op. cit., pp. 15-16. Sobre la designación de corregidor a petición de parte, Bermúdez Aznar, El corregidor en Castilla..., op. cit., pp. 124-126. 
la provincia. Por su parte, los conflictos con Alcaraz se renovarían en 1478, cuando Isabel I, alcanzada la paz con el marqués de Villena, se sirve de la milicia regia para reponer al corregidor; y en 1485 cuando, aprovechando la guerra con Granada, la ciudad rechaza nuevamente al oficial regio, produciéndose una dura represión. En este sentido, hay que tener en cuenta que, según la información que nos proporciona Lunenfeld, la reina solo había sido capaz de hacer valer la designación de 25 corregidores en 1476, 5 en 1477, y 4 en 1478 y 1479, llegando a 1480 con un total de 44. Aunque la normativa dada a los corregimientos en las Cortes de Toledo de 1480 mejoraría su percepción por las ciudades, la oposición a su nombramiento persistiría, aunque cada vez con menor éxito, como demuestran las Cortes de Valladolid de 1506 (petición 23), cuando los procuradores aceptan la prórroga del mandato del corregidor siempre que medie la residencia del oficio (aunque en las de Burgos de 1512 -petición 13- y de 1515 -petición 7- se retorna a la solicitud de un mandato máximo de dos años más la necesaria residencia) ${ }^{15}$.

En cualquier caso, esta oposición es la que se escenifica con nuestro conocido, Juan Sánchez de Peralta, cuyo nombramiento se inserta en el contexto de política banderiza que aún vive la ciudad, y que enfrenta a los partidarios, victoriosos, de Diego Hurtado de Mendoza, y al bando perdedor de Lope Vázquez de Acuña. Partidarios de este, como el regidor Ferrand Suárez, habrían solicitado la designación, o Ruy Ponce de Écija, procurador del Acuña, habrían recibido al corregidor en nombre de este. Es una circunstancia banderiza excepcional que no volveremos a ver repetida hasta $1465 \mathrm{y}$, entonces, en otras circunstancias. Lo interesante de este supuesto es que, como en la generalidad de oposiciones, no se reprocha al monarca su derecho a designar corregidor, sino la oportunidad de la designación, es decir, se valora las circunstancias que han dado lugar al nombramiento y se reprocha la lectura incorrecta que de las mismas hace el monarca. No se discute, pues, el derecho, sino la responsabilidad o irresponsabilidad de su ejercicio. Así, cuando Juan II funda su decisión de designar corregidor en los muchos bolliçios e escándalos e insultos y en las muertes de omnes e robos e fuerças e furtos e feridas e otros malefiçios enormes e desaguisados, el concejo, en un pormenorizado escrito de ocho puntos dado el 10 de octubre de 1420, justifica su rechazo al recibimiento en la pacificación de

15. Orella Unzué, J. L.: El delegado del Gobierno Central en Guipúzcoa: estudio históricojurídico del corregidor guipuzcoano durante el reinado de Isabel la Católica (1474-1504). San Sebastián, 1987, pp. 7-8; BERMúdez AzNAR, El corregidor en Castilla..., op. cit., p. 139; BONACHÍA HeRnando, J. A.: «Materiales para el estudio del régimen de corregidores (Burgos, 1458-1465)», Cuadernos de Historia de España, 75, 1998-1999, pp. 135-159; LunENFELd, op. cit., pp. 16-17, 34, 37-40 y 49-51; González Alonso, op. cit., pp. 94-97; y Cortes de los antiguos reinos, ts. III y IV, confrontar las peticiones señaladas con sus correspondientes sesiones de Cortes. 
la ciudad y en la falsedad de los argumentos en los que descansaba la decisión del monarca:

Denunciaban la invalidez de la carta, al no hallarse librada por persona competente para ello ${ }^{16}$.

Afirmaban que ni el concejo, ni la mayor parte de él, había demandado corregidor y que las personas individuales que lo habían solicitado serán personas singulares e muchas de ellas rafeses e avn rogados por otros e que serían otrosí tales personas que eran coronados e por los malefiçios que fasian pedian seer remitidos al jues de la eglesia.

Recordaban al monarca que le habían enviado dos peticiones oponiéndose al nombramiento de corregidor y que se hallaban a la espera de que les diera respuesta (siguiendo así su normal curso administrativo que la designación de Juan Sánchez había venido a quebrar).

Manifestaban que el problema de los bandos, que enfrentaba a Acuñas y Mendozas, existía, aun si bien no alcanzaba gran entidad, y que su reducción definitiva competía al monarca, pues los dos nobles señores no se iban a someter a otra voluntad política más que la del rey, reclamando que se diera respuesta al problema convocando a Diego Hurtado y Lope Vázquez a la corte (lo que eliminaba la necesidad del corregidor, pues la resolución del conflicto tendría lugar fuera de la ciudad y su tierra).

Justificaban, así mismo, la oposición en el quebranto económico que les supondría pagar la soldada del corregidor, encontrándose la ciudad y su tierra pobres por causa de los pedidos, monedas y aduanas. Y manifestaban, al tiempo, hallarse en paz y que las justicias ordinarias cumplían correctamente con sus funciones.

Reiteraban el estado de paz en que vivían ciudad y tierra, y el ejercicio de la justicia por los oficiales ordinarios de la ciudad.

Recordaban al monarca que había comisionado al flamante guarda mayor, Diego Hurtado de Mendoza, para examinar las cuentas del concejo, y que se hallaba cumpliendo con dicha función (el recordatorio contribuía a eliminar otros espacio de actuación de la agenda de un posible corregidor).

Y, finalmente, denunciaban al corregidor electo, Juan Sánchez de Peralta, por ser persona sospechosa y por levantar bandos en la ciudad ${ }^{17}$.

La argumentación del concejo resultaba impecable: no procedía el nombramiento de corregidor porque, examinados todos los posibles ámbitos de actuación

16. Véase lo comentado sobre este tipo de argumentos en la nota 3.

17. AMC, LLAA, leg. 185, exp. 6, fols. 21r-26v. 
que podrían quedar sometidos a la autoridad del oficial regio, ninguno proporcionaba razones que justificaran la necesidad de este; y allí donde esta sí podría ser argumentada de alguna manera -los últimos coletazos de la violencia banderiza protagonizada por Acuñas y Mendozas-, se construía un escenario en el que la limitación de esa violencia y su necesaria conclusión por la persona del monarca (no de un representante) y en la corte (no en la ciudad) hacían innecesaria la designación del corregidor. La racionalidad de los argumentos, o al menos el carácter firme de la oposición de la ciudad, darían sus frutos, pues todo apunta a concluir que Juan II retiró el nombramiento del bachiller de Peralta ${ }^{18}$.

Los mismos argumentos fueron reiterados pocos años más tarde, en febrero de $1428^{19}$, con el mismo aparente éxito que en 1420, pues la documentación no vuelve a proporcionar información alguna sobre la presencia de corregidor o sus oficiales en la ciudad y su tierra. Y lo mismo sucede en otro contexto más grave, el 1 de noviembre de 1465, cuando el rey (mediante mandamiento otorgado el 10 de octubre, en Segovia), les ordena recibir, no por corregidor, sino como gobernador de la ciudad, a Alfonso Téllez Girón, a lo que se opone el concejo porque para tan grande fecho commo este non es cosa bastante nin sufçciente para que esta çibdad faga tan grande ynovaçion ${ }^{20}$. Especialmente en este último caso, el contexto político facilitaba, de alguna manera, la respuesta de la ciudad. No obstante, el concejo no acude únicamente a una reevaluación de la capacidad regia para valorar ese contexto, sino también al examen de las propias condiciones personales del oficial electo, el examen de las circunstancias «morales» (entendidas en un sentido amplio) que le hacían singularmente reprobable y suponían un nuevo reproche a la capacidad de elección del monarca. En el caso de Sánchez de Peralta se acude a su descalificación como persona sospechosa y parcial, al denunciarse, en ese escrito de 10 de octubre, que ha mantenido tratos con vecinos revoltosos de la ciudad, acostados de Lope Vázquez y clérigos coronados, todos los cuales estaban incorporados a esa categoría de personas rafeses construida por la ciudad para denunciar a los demandantes de corregidor. La sospecha, o su ausencia, constituían un mecanismo de deslegitimación o legitimación singular, sobre todo si, como en este caso, la denuncia de la parcialidad del corregidor electo se vinculaba a acciones banderizas de cuyo liderazgo se hacía responsable al propio oficial regio: ¿cómo, con qué legitimidad y efectividad podía combatir los bandos un oficial cuyas primeras acciones se habían visto vinculadas

18. Su presencia no vuelve a constar en la documentación. Y tampoco figura en la lista de corregidores de Cuenca elaborada por Jesús Moya. Vid. Moya Pinedo, J.: Corregidores y regidores de la ciudad de Cuenca desde 1400 a 1850. Cuenca, 1977.

19. AMC, LLAA, leg. 187, exp. 3, fols. 46r-47r y 48r.

20. AMC, LLAA, leg. 197, exp. 1, fols. 22v-24r. 
precisamente al levantamiento de bandos? Cuenca no se hallaba sola en el recurso a este tipo de argumentaciones. La denuncia de la parcialidad perseguía la completa deslegitimación del corregidor, al relacionarse con su comportamiento injusto y abusivo, contradictorio con la lógica del oficio. Así sucede en Molina de Aragón, en 1494, con el corregidor bachiller Alonso Téllez, a quien se acusa de parcialidad, solicitándose a los reyes que no le prorrogaran en el corregimiento a cabsa de la much a parçialidad y afçión quel dicho bachiller tubo e tyene con algunas personas desta dicha villa e tierra e por la benemiga e malquerençia que con nos, los suso dichos e con nuestros parientes tubo e tyene ${ }^{21}$.

En cualquier caso, oponerse a la designación de corregidor, y hacerlo con éxito, no era un imposible 22 . No lo era oponerse al recibimiento y tampoco lo era oponerse al ejercicio culposo de un corregidor. El 26 de enero de 1435, el concejo escribía al rey recordándole que el corregidor Rodrigo de Bobadilla se hallaba suspendido en el oficio, que se había designado al bachiller Gutier Muñiz de Mieres juez-pesquisidor para examinar la conducta de aquel, y reclamando la presencia en la ciudad del corregidor, su alcalde y alguacil mayores durante los cincuenta días reglamentarios para que los vecinos pudieran interponer las demandas que estimaran oportunas; según el documento, ya se había interpuesto un buen número de ellas y se habían enviado a la corte ${ }^{23}$. Algo similar sucede en 1456, cuando el rey designa a Juan de Mendoza como juez-pesquisidor para examinar las denuncias hechas por la ciudad contra el corregidor Diego Ferrández de Vergara ${ }^{24}$; y en marzo de 1465, cuando Enrique IV revoca el nombramiento del corregidor Pedro de Salcedo, también ante las denuncias de la ciudad ${ }^{25}$.

Lo mismo ocurre en otras ciudades donde, más allá de la oposición al nombramiento de un corregidor, se escenifica incluso la «deposición» del oficial designado por el monarca. Es el caso de Burgos, donde se expulsa de la ciudad al corregidor

21. Cortés Ruiz, M. ${ }^{a}$ E.: «El corregimiento de Molina durante la Edad Media», en La administración de justicia en la historia de España, actas de las III Jornadas de Castilla-La Mancha sobre investigación en archivos, Guadalajara, 1997. 2 vols., Guadalajara, 1999, I, pp. 51-69.

22. Contrariamente a lo que plantea González Alonso, quien considera que la presentación en la ciudad de la carta de nombramiento hacía imperativa la admisión del oficial, ya que el proceder contrario dejaba al concejo sumido en la ilegalidad. Vid. González Alonso, op. cit., p. 49.

23. AMC, LLAA, leg. 188, exp. 5, fols. 20r y 21v-22r. Hay que tener en cuenta que, por algún motivo, la carta aparece tachada en los libros de actas; por lo que es posible que no llegara a enviarse, o al menos no esta en concreto (acaso otra versión, aunque no se ha conservado).

24. AMC, LLAA, leg. 193, exp. 3, fols. 159v-160 y 161v-162r, y leg. 194, exp. 1, fol. 39r.

25. AMC, LLAA, leg. 197, exp. 1, fols. 23r-v. 
en 1459 (en 1464, además, rechazaría de plano su prórroga por otro año, viéndose Enrique IV obligado a transformar a su representante en la caput Castellae en asistente); en Murcia, en 1452 se expulsa de la ciudad al corregidor y, en 1460, el concejo suspende a Diego López de Puertocarrero en el oficio por sobrepasar los dos años de mandato, viéndose obligado Enrique IV a transformar el oficio, como haría pocos años después en Burgos, en asistente; incluso así, la renovación del asistente en 1462 generó conflictos (Enrique IV hubo de amenazar al concejo con la confiscación de bienes y privación de oficios) que se reprodujeron en 1464, cuando, ante la violenta oposición del concejo a la permanencia del asistente en la ciudad, este hubo de salir huyendo por temor a su vida. Algo parecido sucedió en Sevilla, en 1463, cuando una muchedumbre armada atacó al asistente, siendo el motivo último de este grave conflicto la propuesta hecha por este de imponer nuevas sisas sobre la carne y el pescado; es sintomático que los regidores presenciaran pasivamente la agresión. En Jerez de la Frontera la instalación de un corregidor en 1477 provocó un rechazo tan absoluto en la ciudad que prácticamente dio lugar a la interrupción de la política banderiza hasta la década de 1490, al unirse las diversas facciones urbanas en su lucha contra el oficial real. Y en el área vizcaína los niveles de violencia que hubieron de enfrentar los corregidores se manifiestan de una manera aún más intensa: en 1435, el corregidor Pero González era expulsado de Bilbao porque él fasía desafuero e iba contra los previllejos de la villa; y unos años antes, en 1427, el corregidor Juan Martínez de Burgos resultaría herido en Bermeo y más adelante, en el mismo año, muerto de un tiro de ballesta durante una Junta en Arbildua ${ }^{26}$.

\section{NEgOCIACIÓN Y SINERGIAS EN LA ACEPTACIÓN DE LOS OFICIOS DE CORREGIDOR}

Aunque, como hemos podido comprobar, oponerse resultaba factible y no siempre terminaba en fracaso, esta no fue la conducta generalmente seguida por las ciudades y desde luego no por el concejo de Cuenca: en unos casos, esto se debió al propio contexto político local, ligado a las continuas invasiones de términos cometidas por vasallos de señorío, amparados por sus señores, o a las acciones predatorias a que la nobleza territorial venía sometiendo el alfoz conquense, especialmente en los períodos álgidos de guerra civil; y en otros supuestos, tuvo su causa en un ejercicio de realpolitik, que condujo a asumir la imposibilidad

26. Lunenfeld, op. cit., pp. 16-17; Ruiz Pilares, E. J.: «El papel de los matrimonios en la configuración de las relaciones de poder en las élites bajomedievales castellanas. La aplicación del social networks analysis en Jerez de La Frontera (1475-1500)», Norba. Revista de Historia, 24, 2011, pp. 13-34; y Dacosta Martínez, op. cit., pp. 37-64. 
del éxito de la oposición, tanto más real cuanto más se avanzaba en el siglo y especialmente ya bajo la monarquía isabelina. Lo cierto es que, abocadas a graves enfrentamientos con la nobleza territorial, las ciudades tendieron a preferir la presencia de un oficial regio a la imposición de un poder señorial noble. Así por ejemplo, como recuerda Lunenfeld, durante 1444 y 1445, en pleno conflicto con los infantes de Aragón y antes de la batalla de Olmedo, las ciudades solicitan a Juan II la confirmación de una hermandad para Segovia, el envío de un oficial de paz a Valladolid, la designación de corregidor en Ávila, y el nombramiento de un asistente para Burgos ${ }^{27}$.

Sin embargo, en pocas ocasiones este reconocimiento supone sencillamente la aceptación de la inferioridad política de la ciudad o de su vulnerabilidad frente a las injerencias del aparato central de gobierno, pues pocos son los casos en los que el recibimiento del corregidor opera en términos de aceptación pura y simple. Así, el 10 de noviembre de 1483, el concejo de Cuenca escribe al virtuoso sennor Ruy Gómez de Ayala, manifestándole el grand contentamiento que su designación de corregidor les ha producido, y que han acordado recibirle por servir a los reyes y por el afecto que sienten hacia su persona. Halagos, políticos, dirigidos a ganarse la buena voluntad del oficial regio, sí, pero que encuentran una suerte de equilibrio perfecto en las muestras de afecto y consideración hacia la ciudad que había expresado Ruy Gómez, en una carta anterior a la del concejo, de 20 de octubre, en la que les notifica su nombramiento y el alto valor en que lo tenía, pues a sus altesas besé las manos porque me mandaron estar en compannía de tan nobles sennores e de tanto meresçimiento; en la misma línea, el comendador mayor escribía el 18 de octubre a Cuenca rogando al concejo que recibiera a su primo en el oficio, el qual es tal persona commo esa çibdad cumple y que mirará mucho por el bien e provecho della e guardará muy enteramente la justiçia ${ }^{28}$. Si Cuenca consideraba necesario ganarse la buena voluntad del nuevo corregidor, este no operaba de manera distinta en su relación con el concejo. En ambos casos, la evaluación de la calidad moral (política) de cada parte conducía a un juicio de valor en positivo.

Quizás donde sí se verifica de una manera más clara ese proceso de aceptación pura sea en las prórrogas de los corregimientos. En estos casos y en ausencia de reclamación de la ciudad, parece razonable la continuidad de un oficial en el que el concejo ha encontrado un colaborador en las tareas de gobierno y en la defensa de los intereses urbanos. Así sucede, por ejemplo, con la prórroga del corregimiento

27. LunENFELD, op. cit., p. 16.

28. AMC, LLAA, leg. 205, exp. 1, fol. 42v y $72 \mathrm{r}$. 
de Pedro de Barrientos, en marzo de 1470; de Juan Osorio, en septiembre de 1479, y nuevamente en agosto de 1482 cuando, además, los reyes justifican la decisión en la propia alta consideración en que le tiene el concejo, lo que no resulta un elemento puramente discursivo ya que, en carta de 5 de julio de 1482, Cuenca había solicitado a los reyes que no prorrogaran el corregimiento por las fatigas de la çibdad e su tierra, pero que, si insistían en designar nuevo corregidor, que prorrogaran en el oficio a Juan Osorio, por el conosçimiento que de él se ha (en un nuevo ejercicio de valoración de la calidad moral del agente regio). Con criterio en todo similar, ante la prórroga del corregimiento de Ruy Gómez de Ayala, la ciudad también solicitó a este, el 13 de febrero de 1484, que nombrara nuevamente por su alcalde mayor al bachiller Alonso Díaz de Toledo, quien había ejercido la justicia bien y a contentamiento de todos ${ }^{29}$. Especialmente los dos últimos casos ejemplifican el grado de colaboración, de entendimiento, que se podía alcanzar entre concejo y agentes regios. El caso de Juan Osorio, además, ilustra el modo en el que la ciudad manipula, en su propio beneficio, el proceso de designación de corregidores: manifestando su oposición a todo nombramiento, pero su aceptación condicional de Juan Osorio, Cuenca alcanzaba a lograr el fin perseguido, es decir, en un marco en el que una designación parecía cierta, la ciudad se aseguraba de que el nombramiento recayera en el agente adecuado. Idéntico proceder puso en práctica en el caso del bachiller Alonso Díaz.

Como se ha podido comprobar, en última instancia, ni siquiera estas aceptaciones «puras» constituyen un reconocimiento «en blanco» del corregimiento. De hecho, no resultó precisamente inusual someter el recibimiento del oficial al cumplimiento de algún tipo de condición, negociándose de esta manera también el recibimiento de los corregidores. Habitualmente, esta negociación se circunscribió al salario que llevaría el agente regio. Es el caso de la recepción, en agosto de 1434, del corregidor Rodrigo de Bobadilla, en el que Cuenca acuerda cumplir la carta regia de nombramiento, salvo en lo tocante al salario, que rechaza apoyándose en la legislación de Cortes, citando expresamente las de Zamora, de 1432, en las que, en respuesta a su petición 11, el rey se había comprometido a exigir el pago del salario del corregidor a aquellos por cuya causa se hubiera tenido que designar al oficial ${ }^{30}$. El 5 de abril de

29. AMC, LLAA, leg. 198, exp. 4, fols. 4v y 5v; leg. 201, exp.1, fols. 89r y 90r; leg. 203, exp. 2, fols. 289r y 290v-291r, y 261v; leg. 205, exp. 3, fol. 18r.

30. Así mismo, en las de Ocaña de 1422, en su petición 2, los procuradores habían solicitado que el informe o pesquisa que pedían que se hiciera previamente a la decisión de designar corregidor, fuera satisfecho por la parte que resultara responsable. Cfr. AMC, LLAA, leg. 188, exp. 6, fols. $10 \mathrm{v}-11 \mathrm{v}$; y Cortes de los antiguos reinos, t. III, confrontar las peticiones señaladas con sus correspondientes sesiones de Cortes. 
1465, es el propio corregidor, Pedro de Taboada, alcaide de Cuenca, quien, tras ser recibido, renuncia al salario puesto por el rey y se somete al que acuerde la ciudad; esta decidiría, el 3 de mayo, rebajar a 200 mrs los 300 mrs diarios concedidos por Enrique IV ${ }^{31}$.

El impacto que el salario de los corregidores y otros oficiales regios tuvo sobre las arcas municipales y la voluntad urbana de hacer frente a dichos pagos, han sido objeto de análisis enfrentados dentro de la historiografía castellana. Es cierto que las ciudades utilizaron como argumento de oposición al recibimiento de corregidor, e incluso a su posible nombramiento en la corte, la mala situación económica del concejo y su tierra y lo gravoso que sería para aquella el nombramiento de estos oficiales. Cuenca se había servido, entre otros de mayor peso, de este argumento en su oposición al recibimiento de Sánchez de Peralta en 1420, y seguirá acudiendo a esa línea argumental tan tarde como $1483^{32}$. ¿Hasta qué punto esta denuncia de la debilidad económica de las ciudades no constituyó un mero recurso retórico? Bonachía Hernando ha ilustrado el peso económico que llegó a suponer para Burgos el pago de estos salarios, tomando el caso del corregidor Fernando de Fonseca, cuyo sueldo, de $400 \mathrm{mrs}$ diarios, equivalía a un $65,66 \%$ de la renta de la barra en 1458 (se trata de la renta más sustanciosa para la ciudad que, en ese año, supuso unos ingresos de $214.000 \mathrm{mrs}$ ). Entre ese año de 1458 y 1461, Burgos hubo de hacer frente a los últimos pagos del salario de Fonseca, al sueldo del pesquisidor enviado para entender del levantamiento popular sufrido en la ciudad en 1459 , y a las cantidades con las que el concejo acordó indemnizar a los represaliados por dichos incidentes, viéndose obligada a poner en pública subasta un solar del concejo, y a cargar parte de los gastos en préstamos y sisas. Una situación similar, aunque no tan extrema, experimentó Murcia cuando, en marzo de 1457, recibió a Diego López Puertocarrero y, ante la falta de efectivo y para adelantarle $10.000 \mathrm{mrs}$ de su salario, se vio obligada a arrendar de manera apresurada la sisa y libras de la carne y pescado del año siguiente; cosa que se vio en la necesidad de repetir en 1460, acudiendo incluso al préstamo de $10.000 \mathrm{mrs}$ hecho por un regidor para atender al pago del salario de Puertocarrero ${ }^{33}$. Aunque, como estos ejemplos muestran, el coste de la presencia

31. AMC, LLAA, leg. 197, exp. 1, fols. 23r-24v, y exp. 3, fols. 32r-45r.

32. El 21 de abril, el concejo escribía a los reyes expresando su preocupación por el posible nombramiento de un corregidor para la ciudad, alegando hallarse la ciudad y su tierra «muy gastadas y fatigadas», y advirtiendo de que no podría hacer frente al pago de los salarios del corregidor y sus oficiales. Vid. AMC, LLAA, leg. 204, exp. 3, fol. 151v.

33. Bonachía Hernando, op. cit., pp. 135-159; y Bermúdez Aznar, El corregidor en Castilla..., op. cit., pp. 159-160. 
del corregidor y sus oficiales en las ciudades castellanas pudo ser significativo, no parece que el impacto de estos gastos y de la fiscalidad regia en su conjunto alcanzara dimensiones similares a las observadas en la vecina Corona de Aragón, pues en Castilla no hubo necesidad de acudir a emisiones (menos aún masivas) de deuda pública para solventar los problemas de liquidez de ciudades y villas (aunque sí tuviera que recurrirse, en ocasiones, al préstamo y a la disposición de los ingresos futuros de algunas rentas). Además, nos consta que en muchos casos los sueldos de estos oficiales fueron objeto de negociación, alcanzándose recortes significativos que contribuyeron a reducir su peso sobre los erarios municipales. Ya hemos visto cómo esto sucede en Cuenca, y lo mismo comprobamos en Jerez en 1459, cuando el corregidor, a la sazón el marqués de Villena, reclama el pago de los $170.000 \mathrm{mrs}$ del salario fijado por el rey y la ciudad se compromete a satisfacer tan solo $80.000 \mathrm{mrs}$, llegando ambas partes a un compromiso final de $100.000 \mathrm{mrs}$. En todo caso, como señala Lunenfeld para el período isabelino, los corregidores mostraron su disposición a reducir sus salarios en períodos de penuria hacendística para la ciudad; y esta supo, además, arbitrar procedimientos para presionar económicamente a los corregidores: obligarles a designar un fiador de fuera del municipio para hacer frente a las posibles indemnizaciones a que diera lugar el juicio de residencia y retener el tercio final del salario con la misma finalidad (así sucede en Cáceres, León, Ciudad Real, Carrión, Guádix y Málaga), o forzarles a correr con el pago de los salarios del teniente y alcalde mayor (como sucede en Murcia) ${ }^{34}$. Así mismo, debe tenerse presente que, en

34. Idem, pp. 150-151; y Lunenfeld, op. cit., pp. 83-86. Aparte de estos procedimientos y de la negociación del salario, siempre quedaba a la ciudad la opción de retrasar los pagos o de no pagar, al menos en el corto plazo. Así por ejemplo, en octubre de 1461, el corregidor declaraba quito al concejo de Cuenca de las cantidades debidas de su salario, salvo de $15.500 \mathrm{mrs}$ que aún se le adeudaban. En febrero de 1462, el corregidor requería el pago de su salario, afirmando que llevaba en el ejercicio del cargo cuatro meses y no se le había satisfecho cantidad alguna. En marzo de 1465, en respuestas a unas prendas tomadas sobre bienes de Juan Hurtado de Mendoza por el corregidor saliente Pedro de Salcedo, el concejo escribía a este rogándole que retornara aquellas y enviara un representante para hacer cuenta de lo que se le debía de su salario; casi con toda seguridad, prendas y deuda estaban íntimamente relacionadas; sabemos que la deuda seguía viva tres meses después, en junio. Años más tarde, el 22 de abril de 1483, el concejo rechazaba el requerimiento presentado por Ferrando Navarro, criado del corregidor Juan Osorio, para que se le pagara el salario debido desde el 23 de septiembre de 1482 (había sido recibido el 26 de agosto de ese año, pero no había iniciado sus funciones hasta el 23 de septiembre); en esta ocasión, el concejo recurrió a uno de sus argumentos favoritos, el legal, denunciando defecto de forma en el apoderamiento del criado, que le inhabilitaba para representar a su señor y, por lo tanto, presentar ninguna reclamación, añadiendo, como argumento final, la ausencia del corregidor de la ciudad, en contravención de lo dispuesto en las leyes de Toledo de 1480. Cfr. AMC, LLAA, leg. 195, 
ocasiones, si bien la presencia del corregidor podía resultarle costosa a la ciudad en términos económicos, en un plano social y de poder podía constituir un activo importante, al menos para la elite gobernante que se iba a beneficiar de dicha presencia. Es lo que señala Guerrero Navarrete precisamente para esos años tan duros experimentados por Burgos, entre 1458 y 1461, pero también para otros momentos de especial dificultad política para el regimiento, como 1411, 1457, 1463 o 1465. En estas ocasiones, singularmente 1411 y 1465, la presencia del corregidor venía a consolidar la posición de poder del regimiento, contestada por sectores importantes de la comunidad urbana; y este apoyo bien valía soportar el coste de ese salario ${ }^{35}$.

En cualquier caso, en principio, la negociación del salario del corregidor apenas parecía tener relevancia política, afectando únicamente a las expectativas de ingresos de este oficial; pero forzar al corregidor a negociar desde el primer momento su presencia consentida en la ciudad, sí la tenía ${ }^{36}$. Como también la tenían otras condiciones igualmente de apariencia inocua, como el juramento que se obligó a prestar a Diego Ferrández de Vergara, en octubre de 1454, comprometiéndole a no tomar a su servicio rufianes ni vagabundos, ni permitir que lo hicieran su alcalde y alguacil mayores (sabemos que, en 1456, sería sometido a una pesquisa ante las denuncias presentadas contra él por la ciudad) ${ }^{37}$. No obstante, en otras ocasiones la negociación podía alcanzar a aspectos más sustanciales. Así, el 6 de octubre de 1474, el bachiller Diego Gómez, vecino de Cuenca, era recibido en el corregimiento de la ciudad en representación de Juan Osorio, y juraba un capitulado de quince artículos que limitaba sensiblemente la capacidad de acción del corregidor y sus oficiales y que, así mismo, en la defensa de los intereses de la ciudad, conducía a alinearle contra los intereses de los monarcas ${ }^{38}$.

exp. 2, fol. 30v; leg. 195, exp. 4, fols. 58r-v; leg. 197, exp. 3, fols. 12r-v; leg. 197, exp. 4, fol. 54r; leg. 204, exp. 3, fols. 153v-154r y 155r.

35. Guerrero Navarrete, op. cit., pp. 59-102.

36. Sobre el uso por las ciudades del acto de juramento del corregidor para imponer condiciones al ejercicio del oficio, véase Bermúdez Aznar, El corregidor en Castilla..., op. cit., p. 141.

37. AMC, LLAA, leg. 197, exp. 3, fols. $15 \mathrm{v}$ y $14 \mathrm{v}$

38. AMC, LLAA, leg. 200, exp. 3, fols. 9r-v y 10v-12r. 
1. Capítulos jurados por Diego Gómez, en nombre y representación del corregidor electo Juan Osorio (Cuenca, a 6 de octubre de 1478)

Primero. Obedecer los mandamientos de los reyes.
Noveno. Conformarse con la guarda mayor y regidores para no recibir oficios acrecentados, según estipulan las leyes del reino y los privilegios de la ciudad.

Décimo. Guardar las honras y preeminencias de la guarda y los regidores.

bien público.

Tercero. Evitar todo daño al concejo y comunicar a los reyes los peligros que conozca para ponerles remedio.

Cuarto. Él y sus alcaldes mayores librarán los pleitos con justicia.

Quinto. No aceptar demandas contra los alcaldes ordinarios por los asuntos que hayan dejado sin resolver.

Sexto. Guardar el pro de la ciudad y su tierra, y las ordenanzas hechas y que se harán por la guarda mayor y los regidores.

Séptimo. Guardar los propios y rentas del concejo.

Octavo. Someterse a residencia al cumplirse su mandato.
Undécimo. Incorporar a su escribano únicamente a las causas criminales, no a las civiles.

Duodécimo. No consentir la enajenación de vasallos, términos y jurisdicción de la ciudad.

Decimotercero. No compartir residencia con ningún vecino o morador de la ciudad.

Decimocuarto. Ni él, ni sus alcaldes y alguaciles mayores, ni sus escribanos, llevarán derechos demasiados, por encima de los fijados por el concejo.

Decimoquinto. No entender de las cosas pasadas, así la pesquisa de Gerónimo de Valdivieso como otras cosas, sin mandato de los reyes.

A simple vista, el capitulado se presentaba como un conjunto de disposiciones que apenas afectaban a la capacidad de acción del corregidor, pues se insertaban sencillamente en el contenido y la naturaleza de sus funciones: obedecer los mandatos regios, proteger a la ciudad y tierra de todo mal, hacer justicia, someterse a residencia, entre otros artículos, constituían obligaciones propias del oficial regio. Sin embargo, el concejo fue capaz de ir más allá en la definición de las competencias del corregidor y sus oficiales, forzando una lectura claramente «pro-urbana» de aquellas: los artículos quinto y undécimo venían, el primero, a proteger a miembros de la elite de participación de la ciudad -el segundo escalón 
de la clase dominante conquense- de una posible acción negligente y, el segundo, a reservar a miembros de esa misma elite la participación en la llevanza de los procedimientos civiles y, por lo tanto, la participación en los ingresos derivados de esa actividad pública; el artículo décimo podía resultar simplemente retórico, la demanda de una muestra formal de respeto sin otro contenido o consecuencia sustantivos, pero los artículos sexto, noveno y decimocuarto expresaban con gran claridad el modo en el que debía entenderse el desenvolvimiento de las relaciones de poder en la ciudad, especialmente entre regidores (y guarda mayor) y corregidor, pues si el artículo noveno obligaba al corregidor a «conformarse» con esos oficiales urbanos (en una medida que, por otra parte, suponía implementar la legislación regia, lo que contribuía a molificar esa obligación de «conformación»), los otros dos artículos reservaban a los oficiales concejiles la aprobación de ordenanzas y la fijación de tasas (incluidas aquellas que regulaban el pago de gestiones realizadas por el corregidor y sus oficiales); además, el artículo decimoquinto limitaba sustancialmente la capacidad de acción del corregidor al impedirle abrir causas relacionadas con las pesquisas y otras actuaciones ejecutadas por jueces de términos, claramente beneficiosas para el concejo y que este, lógicamente, prefería no ver reexaminadas (esta fue la única condición a la que Diego Gómez puso salvedad, jurando respetar lo dispuesto en este artículo salvo en el caso de mediar querella de parte); y, finalmente, el artículo duodécimo colocaba al corregidor en la misma situación en la que la ciudad había puesto con anterioridad a otros oficiales regios, la necesidad de defender la integridad de su jurisdicción incluso contra la voluntad regia.

Esta no fue la única ocasión en la que el concejo «forzó la voluntad» del corregidor electo. Tanto más interesante que esta, resulta la experiencia de Pedro de Taboada, alcaide del castillo de Cuenca. En agosto de 1461, ante el obispo Lope Barrientos y en su palacio episcopal, Taboada se había comprometido a no amparar en el castillo a rufianes, así como a entregar a los individuos que le fueran reclamados. Menos de cuatro años más tarde y en un contexto político de mayor gravedad, el 1 de abril de 1465, por que la dicha çibdad sea de ello e de sy más segura, se fiso e ordenó [una] escriptura de confederaçión e amystad entre la dicha çibdad e el dicho alcayde, signada en el cortijo de la fortaleza. Entre otros extremos, en ella se acordaba mantenerse ambas partes en paz; si el rey decidía entregar la fortaleza a persona poderosa, el alcaide suplicaría al monarca la revocación del mandamiento y, si se viera obligado a ello, daría un plazo de veinte días a la ciudad para levantar palenques frente al castillo (en el ínterin, la ciudad aceptaba no erigir otros, pues ya había levantado o amenazado con 
levantar uno el 29 de marzo) ${ }^{39}$. Cuatro días más tarde, el 5 de abril, Pedro de Taboada presentaba ante el concejo su carta de nombramiento de corregidor, era recibido, juraba el oficio y renunciaba en los regidores la fijación de su salario. Su nombramiento como corregidor había sido otorgado por el rey en Madrid, el 25 de marzo ${ }^{40}$. Cuesta no creer que, entre la recepción por Taboada del nombramiento regio y su recibimiento en la ciudad, no se negociara tanto la escritura de confederación como la renuncia al salario. Sin duda, ambos extremos y su trayectoria de cooperación con la ciudad como alcaide, facilitaron su rápido recibimiento por la ciudad. Es cierto también que las circunstancias de 1465, especialmente dramáticas para Enrique IV y también muy graves para Cuenca, debido a las acciones de la nobleza rebelde en la zona, tendieron a facilitar el acuerdo entre los partidarios del monarca (es decir, la ciudad, el alcaide-corregidor, y también el obispo y algunos miembros de la nobleza que, aunque no hayan estado presentes en las líneas anteriores, jugaron un papel determinante). En cualquier caso, la relación del nuevo corregidor con el concejo no podía ser considerada menos invasiva y más cooperativa.

En cualquier caso, Cuenca no fue una excepción. Sabemos que en otros concejos el recibimiento del corregidor fue también objeto de negociación, cuando menos en relación con su salario y el de sus oficiales pero, en algunas ocasiones, así mismo alcanzando el contenido de sus competencias.

39. AMC, LLAA, leg. 195, exp. 2, fol. 37r; leg. 197, exp. 1, fols. 18v-20r. La amenaza de entrega del castillo no era ilusoria. El 15 de junio de 1465, se presentaba ante el concejo una carta del rey, dada en Salamanca el 5 de junio pasado, en la que reconocía haber tenido la intención de entregar la fortaleza al arzobispo de Toledo, y confirmando su intención de mantenerla en el realengo (a cambio, manifestaba su intención de darle al arzobispo las fortalezas de Medina del Campo y de Ávila). Cfr. AMC, LLAA, leg. 197, exp. 4, fol. 53r. También la construcción de estos palenques está documentada. Sabemos que en noviembre de 1461, García de Ayllón, criado del alcaide, presentaba ante el concejo una carta del rey, ordenando el derribo de un adarve construido por la ciudad frente al castillo, cuando el levantamiento de los infantes de Aragón de 1448-1449. Debieron obedecer la carta, pues el 29 de marzo de 1465 (conviene tener presente que unos días antes de la concordia), el concejo autorizaba al alguacil mayor y a Alonso de Arcas, procurador síndico, para tomar la madera que encontraran en la ciudad con el fin de construir un palenque ante el castillo. Cfr. AMC, LLAA, leg. 195, exp. 2, fol. 36r; leg. 197, exp. 1, fols. 7v-8r.

40. AMC, LLAA, leg. 197, exp. 1, fols. 23r-24v. De este conflicto me he ocupado con detalle en «1465: Para que sean e estén para la corona real. Pacto político, realengo concejil y guerra civil en Castilla», en Nieto Soria, J. M. y Villarroel González, Ó. (coords.): Pacto y consenso en la cultura política peninsular (siglos XI al XV). Madrid, 2013, pp. 361-386. 
2. Capítulos jurados por el corregidor Diego López Puertocarrero (Murcia, a 23 de marzo de 1457)

Primero. Guardar el servicio y señorío del rey, sus pechos y derechos, y el bien común y poblamiento de la ciudad.

Segundo. Guardar los fueros, privilegios, libertades, usos y costumbres de la ciudad.

Tercero. Librar los pleitos con justicia y diligencia.

Cuarto. Defender la jurisdicción de la ciudad frente a cualquier juez, eclesiástico o seglar, foráneo.

Quinto. Él y sus alcaldes mayores cobrarán solo el diezmo de las entregas que hagan, por la cuantía efectivamente hecha.

Sexto. Someterse a la tasa de carcelería que se incorpora.

Séptimo. Respetar la tasa de los derechos que llevan los escribanos por la llevanza de las causas civiles y criminales, salvo si el procedimiento es determinado personalmente por el corregidor y si pasare por el escribano que él lleve, quien podrá llevar los derechos doblados.

Octavo. Respetar el derecho del concejo a nombrar a los ejecutores, almotacenes, alcaldes de la huerta y sobrecequieros.

Noveno. Prohibir al escribano que lleve consigo entrometerse en las competencias de los escribanos de la ciudad y el escribano mayor del concejo.

Décimo. Dictar sentencia con independencia de que las partes hayan asegurado las costas o no.
3. Capítulos jurados por el corregidor Juan de Ribera (Junta General de Segura, noviembre de 1491)

Primero. Guardar el cuaderno, ordenanzas, cartas reales y privilegios de la provincia.

Segundo. Jurar y prometer no dar providencia ni mandamiento contra ellos.

Tercero. No entrometerse en quitar ni poner alcaldes ordinarios, ni de hermandad, ni otros oficiales de villas y lugares.

Cuarto. No asumir pleitos de los que ya conozcan los alcaldes ordinarios sin que las partes apelen a su tribunal.

Quinto. No continuar los pleitos al finalizar su mandato.

Sexto. Las causas sustanciadas serán devueltas a los alcaldes ordinarios en cuya jurisdicción vivan los reos.

Séptimo. Ningún acompañante del corregidor hará de procurador, de vecino de la provincia, contra las sentencias de los alcaldes donde son vecinos.

Octavo. Ni hará ni mandará hacer pesquisa por causa civil.

Noveno. Guardar los privilegios, buenos usos y costumbres de las villas y lugares de la provincia.

Décimo. Él, sus oficiales y escribanos, se ajustarán al arancel de derechos que la provincia tiene aprobado de los reyes. 
Como ilustran las tablas 2 y $3^{41}$, la extensión de estos capitulados podía llegar a cercenar de manera significativa las competencias de estos oficiales, algo que se comprueba especialmente en los ámbitos económico (sometimiento a tasas impuestas por la ciudad o negociadas por esta, no con el corregidor, sino con los reyes) y de oficios públicos (limitando, especialmente en el caso guipuzcoano, la capacidad de intromisión del corregidor, no solo en las competencias, sino incluso el nombramiento de determinados oficiales concejiles y extra-concejiles pues, como consecuencia del capitulado, los reyes no solo confirmarían este, sino que, en su línea, prohibirían al corregidor arrendar el oficio de merino y designar al promotor fiscal de la provincia -respondiendo así a una queja ya antigua de la provincia-y poco más tarde, el 20 de diciembre de 1491, aprobarían un arancel al que sujetarían los beneficios económicos del corregidor y su personal). Contemplada así la acción del corregidor, se comprende que pudiera llegar a ser percibida de manera positiva, viéndose en este oficial regio un colaborador más que un competidor. Esto no quiere decir que las ciudades y sus elites gobernantes no procuraran verse libres de él, sino que, en aquellos casos (cada vez más numerosos a medida que avanza la centuria) en los que la presencia del corregidor se hizo imposible de contener, poder negociar e incluso imponer unas condiciones de recibimiento -de mínimos o incluso de máximos- (allí donde efectivamente se pudo), contribuyó a transformar al agente regio en un cooperador en las tareas de gobierno de la ciudad y en el no menos importante aseguramiento de la posición de poder de las elites urbanas, como hemos tenido ya ocasión de comentar.

En este último sentido, la práctica generalidad de los corregidores de Cuenca mantuvo una clara línea de colaboración con las autoridades urbanas en el gobierno y defensa de la ciudad. No me voy a detener en estas cuestiones, por ser más conocidas, pero es de reseñar su implicación en la defensa de la jurisdicción urbana frente a las invasiones de términos llevadas adelante por los vasallos de los señoríos comarcanos. Su defensa de la concepción del realengo les llevó a alinearse con la ciudad frente al monarca, como sucede en mayo de 1440, cuando el bachiller y corregidor Gómez Díaz de Vasurto otorga, junto a los demás integrantes del ayuntamiento, una carta al rey protestando por la entrega de cuatrocientos vasallos de Cuenca a Pedro de Acuña, que concluía con la petición de que proveyera por manera que esto no pase, en lo qual faredes lo que cunple a vuestro seruiçio e acreçentamiento desa vuestra corona e a prouecho desta vuestra çibdat, e a los

41. El documento que recoge los capítulos jurados por Diego López Puertocarrero se encuentra publicado en Bermúdez AznAR, El corregidor en Castilla..., op. cit., pp. 269-273; los capítulos jurados por Juan de Ribera se encuentran citados en Orella Unzué, op. cit., pp. $38-41$. 

PRAXIS DE UNA RELACIÓN POLÍTICA HASTA LA MONARQUÍA ISABELINA

moradores della faredes mucho bien e mucha merçed (petición que, a contrario sensu, constituía toda una admonición $)^{42}$. Y, en la misma línea de acción, su defensa de ciudad y tierra no solo frente a algunas (pocas, es cierto) usurpaciones de términos intentadas llevar adelante por miembros de la elite urbana, sino especialmente frente a las acciones más numerosas, agresivas y lesivas emprendidas por la nobleza territorial, aunque aquí el éxito fuera reducido, tanto en la lucha con la nobleza como en el reconocimiento a que aspiraba algún corregidor, como Pedro de Salcedo, quien, ante el impago de su salario y otros gastos hechos en defensa de la ciudad, el 15 de marzo de 1465, escribía al concejo recordándole todo lo que había hecho por la ciudad y lamentando

la descortesía que contra mí todos sennores cometistes [viéndose obligado a actuar] syn ayuda del sennor obispo e de vosotros [...] por que la dicha çibdad e los vesinos de ella estouiesen fauoresçidos [y] vosotros sennores ovo conoçimiento de los seruiçios e honrras e trabajos e peligros que yo por vosotros pasé, e avn quedo en asás, que tomé por enemigos, por respecto de vosotros, quantos ommes e nobles ay en esa comarca e avn los más de este reyno, los quales me solían faser muy grandes honrras e acatamientos e fallaua sus puertas abiertas quando las quería; lo qual todo yo perdy por vosotros, e la postre [no] aveysme dado el gualardón, desto non me marauillo $[\ldots]^{43}$.

Esa línea de colaboración con el concejo queda ilustrada, así pues, por el grado de activa y positiva participación en las acciones cotidianas de gobierno en la ciudad. Evidentemente, esto dependió de la persona del corregidor -de su mayor o menor disposición a colaborar con las autoridades urbanas-, de las elites gobernantes de cada ciudad y villa, del contexto político -constituyendo los momentos más duros de los diversos períodos de guerra civil, las coyunturas más idóneas donde encontrar esta colaboración- y del período formativo de la institución -la extensión del régimen de corregimientos durante la monarquía isabelina favoreció una mayor injerencia de estos oficiales en los asuntos urbanos-. Gibert, aunque desde una óptica excesivamente jurídico-institucionalista, en su estudio sobre el concejo de Madrid contempla la presencia del corregidor y su participación en las acciones de gobierno en términos de normalidad ${ }^{44}$.

42. AMC, LLAA, leg. 190, exp. 2, fols. 9v-10r.

43. AMC, LLAA, leg. 197, exp. 3, fols. 11v-12r.

44. Gibert y Sánchez de la Vega, R.: El concejo de Madrid. I. Su organización en los siglos XII al XV. Madrid, 1949, en general y especialmente pp. 193-210. De hecho, Lunenfeld, siguiendo a Gibert, llega a afirmar que la presencia de los corregidores no fue sentida negativamente en todos los casos pues los regidores, con el fin de evitar la intervención mediadora del corregidor, 
Una normalidad, una cotidianeidad que, más allá de la oposición al nombramiento o al recibimiento del corregidor y una vez actuando este efectivamente, en Cuenca queda ilustrada por el reducido número de ocasiones en que han quedado documentados roces, de importancia o no, entre el corregidor y sus oficiales, de una parte, y la ciudad, de otra. Aunque es cierto que, de haberlos, los contenciosos judiciales se sustanciarían en otras instancias, al menos debería haber quedado constancia de ellos en los libros de actas del concejo, y apenas ha quedado conservada alguna queja, lo que en sí mismo resulta significativo. Así, el 9 de diciembre de 1463, el concejo procedía a nombrar a un procurador síndico, manifestando su protesta el alcalde y alguacil mayores por considerar que ello no era en servicio del rey -la protesta no fue atendida por las autoridades urbanas-; tampoco alcanzó demasiada entidad otro conflicto, el 23 de diciembre de 1483, este provocado por la aceptación de los regidores del traspaso de un oficio de caballería de la sierra en una sesión de ayuntamiento de la que se había ausentado el alcalde mayor, bachiller Alonso Díaz de Toledo, por oponerse a ello y porque el regidor Alonso de Alcalá había afirmado que el regimiento podía tomar esa decisión incluso con su oposición; más importante pero, como los anteriores, de escasa consecuencia, había sido el contencioso surgido a lo largo del mes de julio de 1483, cuando el concejo solicitó a los reyes la revocación del corregimiento, toda vez que el corregidor, Juan Osorio, se hallaba perdido en tierra de moros (finalmente se sabría de su muerte), a lo que se opusieron tanto el alcalde mayor como el guarda mayor ${ }^{45}$.

Finalmente, expresión singular de lo que podía representar esa "participación normalizada» en la vida política de la ciudad, es el propio capital humano que se hacía presente en aquella. No me refiero a la disposición, a la voluntad mostrada hacia el concejo por el corregidor y sus oficiales en tanto que tales, sino en la relación más estrecha que podían tener con el cuerpo sociopolítico urbano simplemente por el hecho de que, en muchos casos, estos individuos eran vecinos de la ciudad. Evidentemente, me estoy refiriendo a alcaldes y alguaciles mayores, no a los corregidores, estos siempre foráneos respecto del concejo -lo mismo cabe señalar para los escasos tenientes de corregidor documentados en Cuenca.

Para el período que analizamos, tengo documentadas 885 sesiones de ayuntamiento, solo en 335 de las cuales se encontraron presentes el corregidor y/o

procuraron adoptar sus acuerdos mediante mayorías amplias que hacían innecesaria aquella. Vid. LUNENFELD, op. cit., p. 43.

45. AMC, LLAA, leg. 196, exp. 1, fol. 49v; leg. 205, exp. 3, fol. 31v; y leg. 205, exp. 2, fols. $78 \mathrm{v}-79 \mathrm{r}$. 
sus oficiales. Esto significa que la injerencia de estos agentes regios en las actividades del concejo no llegó a alcanzar al 38\% de las sesiones de ayuntamiento, lo que representa un porcentaje significativo pero no excesivo en el conjunto del período y de la vida concejil de Cuenca. Así, el nivel de injerencia, en términos simplemente cuantitativos, podía considerarse tolerable; más aún si tenemos en cuenta que solo en 160 de esas sesiones estuvo presente el corregidor, de manera que este hubo de delegar las gestiones del corregimiento en sus alcaldes y alguacil mayores en 175 sesiones de ayuntamiento. Esto supuso dejar en manos de este personal la presencia y actuación en el 52,24\% de las sesiones a las que asistieron el corregidor y/o sus oficiales; lo que hace especialmente interesante el conocer quiénes eran estos individuos que, en la práctica, se responsabilizaban directamente de más de la mitad de las presencias de estos agentes regios en las sesiones de ayuntamiento.

\begin{tabular}{|l|c|c|c|}
\hline \multicolumn{4}{|c|}{ 4. Condición de vecindad de los oficiales del corregidor $(1417-1480)^{46}$} \\
\hline & Vecino & Foráneo & Desconocido \\
\hline Alcalde mayor & 10 & 10 & 8 \\
\hline Alguacil mayor & 12 & 9 & 11 \\
\hline Teniente de corregidor & 0 & 4 & 1 \\
\hline
\end{tabular}

El examen de la tabla 4 no deja lugar a dudas en cuanto a la implicación de los vecinos de la ciudad en las tareas de gestión de los corregimientos. Exclusión hecha de los tenientes de corregidor (de los cuatro que constan como foráneos solo uno, Rodrigo de Gaona, desempeñó dicha función en exclusividad; los tres restantes, así como el teniente que figura bajo el rótulo de «Desconocido», simultanearon sus funciones con el servicio de una alcaldía mayor), consta un total de 60 alcaldes y alguaciles mayores, de los que el 36,67\% eran vecinos de Cuenca, el 31,67\% eran foráneos (vecinos de otras ciudades o villas), y para el $31,66 \%$ restante no nos consta fehacientemente la condición de vecindad, aunque sospecho que en la mayor parte de los casos nos encontramos, así mismo, en presencia de vecinos de la ciudad. En cualquier caso, resalta el alto uso que hicieron los corregidores de personal local para el desempeño de estos oficios de justicia en Cuenca; una medida que lubricó las relaciones de poder con el concejo, facilitando no solo la participación del corregidor y sus oficiales en la vida política de la ciudad, sino además simplificando y haciendo más cooperativo el proceso de toma de decisiones. La falta de información similar para 
JOSÉ ANTONIO JARA FUENTE

ENTRE EL CONFLICTO Y LA COOPERACIÓN: LA CIUDAD CASTELLANA Y LOS CORREGIDORES, PRAXIS DE UNA RELACIÓN POLÍTICA HASTA LA MONARQUÍA ISABELINA

otros concejos castellanos hace muy aventurada la extrapolación a estos de lo que sucede en Cuenca, pero el concejo del Júcar y del Huécar no tuvo por qué constituir, en este sentido, una excepción significativa en el panorama político de la Corona de Castilla.

\section{Conclusiones}

La presencia de los agentes regios, singularmente de los corregidores y su personal de apoyo, en las ciudades castellanas a lo largo del siglo (y hasta la inauguración de la monarquía isabelina, punto final de este estudio) no supuso necesariamente una injerencia, intromisión y detracción de áreas de decisión del poder local cuantitativa o cualitativamente significativas (intolerables), al menos no en todos los casos. Es así que la ciudad no se presenta como víctima propiciatoria en el proceso de centralización monárquica que se desarrolla, con creciente intensidad, a lo largo del siglo xv. Las ciudades fueron capaces de poner en ejecución una activa política de oposición a los nombramientos de estos oficiales y, en mayor medida, a su recibimiento e incluso a la prorrogación de sus funciones. Una oposición que si, en algunos casos, se materializó en el ejercicio de una violencia, en ocasiones extrema -llegando a concluir en la muerte del oficial regio-, por el contrario, muchas veces se presentó como un instrumento singular en el proceso de negociación de la aceptación de la figura del corregidor. Aquí el término «negociación» es importante, pues el recibimiento del corregidor en la ciudad constituye, en general, la fase final de un proceso de acuerdo dialogado por ambas partes, ciudad y agente regio, en el que las dos agencias hubieron de efectuar renuncias. Desde este punto de vista, el recibimiento del corregidor no representa una derrota del concejo, ya que a través del proceso de negociación las ciudades fueron capaces de atraer las funciones del corregimiento al servicio de sus intereses más directos y de los de sus elites gobernantes; pero el proceso

46. Por obvias razones de espacio, he optado por no insertar las referencias documentales de las 885 sesiones de ayuntamiento, que identifican la presencia de estos oficiales. Para evitar una cita innecesariamente larga, he decidido incorporar las referencias documentales que recogen la primera y última presencia documentadas de cada corregidor y sus oficiales. $C f r$. AMC, LLAA, leg. 186, exp. 5, fol. 59r; leg. 187, exp. 2, fol. 27r; leg. 188, exp. 3, fols. 4r y 10r; leg. 188, exp. 5, fol. 19v; leg. 190, exp. 2, fol. 4r; leg. 190, exp. 3, fol. 12r; leg. 190, exp. 9, fol. 12r; leg. 192, exp. 1, fol. 2r; leg. 197, exp. 3, fol. 14v; leg. 193, exp. 4, fol. 13v; leg. 194, exp. 1, fol. 6r; leg. 197, exp. 2, fol. 55r; leg. 195, exp. 1, fol. 59v; leg. 195, exp. 2, fols. 42r y 44v bis; leg. 195, exp. 4, fols. 61r, 53r, 66r, y 88r-v; leg. 196, exp. 1, fols. 66v y 68v; leg. 196, exp. 2, fol. 113v; leg. 197, exp. 1, fol. 23r; leg. 197, exp. 2, fol. 35r; leg. 197, exp. 3, fol. 3r; leg. 197, exp. 4, fol. 60v; leg. 198, exp. 3, fols. 27r-v; leg. 198, exp. 4, fol. 72v; leg. 200, exp. 3, fol. 13r; y leg. 201, exp. 4, fols. 23r-v. 
de negociación de su recepción tampoco constituye un fracaso para el corregidor, ni siquiera en aquellos casos en los que el recibimiento se ve precedido o acompañado del juramento de capitulados, más o menos extensos, que reducen expresa y formalmente su capacidad de acción pues, en última instancia, el triunfo del corregidor se debe medir por su capacidad para hacerse presente de manera estable en los espacios urbanos.

En todo caso, en el examen de este modelo de relación, debe tenerse muy presente la cronología y el contexto político, pues especialmente los períodos de guerra civil y de mayor presión de los grandes (y no tan grandes) linajes nobles sobre el realengo, facilitaron la generación de espacios políticos de diálogo y acuerdo entre estos representantes regios y unas ciudades hambrientas de protección efectiva.

Es evidente que este modelo de análisis no se ajusta a todos los casos. Hubo concejos donde la política banderiza local alcanzó tal intensidad que la inserción del corregidor resultó inoperante; concejos en los que la presencia de potentes linajes de la nobleza territorial forzó la voluntad del agente regio, reduciéndolo a un colaborador de los intereses nobles. Pero esta no es la imagen general que proporciona la institución. Así, frente a la visión tradicional del ejercicio riguroso o abusivo (también banderizo) del oficio por parte de los corregidores y sus oficiales, cabría considerar otra en la que los agentes regios y las ciudades encontraron espacios de negociación y acuerdo que facilitaron el proceso de toma de decisiones y el desenvolvimiento de las respectivas funciones a ambas partes. Una imagen en la que ambas partes fueron capaces de valorar las sinergias que la colaboración podía conllevar en última instancia. Lunenfeld también se referirá a esta misma «concordia» entre ciudades y corregidores pero para una etapa posterior, entrada ya la monarquía isabelina ${ }^{47}$.

\section{BiBLIOGRAFÍA}

Belenguer Cebriá, E. (coord.): De la unión de coronas al Imperio de Carlos V, congreso internacional, Barcelona, 2000. Madrid, Sociedad Estatal para la Conmemoración de los Centenarios de Felipe II y Carlos V, 2001, 3vols., I, pp. 281-298.

Bermejo Cabrero, J. L.: «La idea medieval de contrafuero en León y Castilla», Revista de Estudios Políticos, 187, 1973, pp. 299-306.

Bermejo Cabrero, J. L.: «Mayoría de justicia del rey y jurisdicciones señoriales en la Baja Edad Media castellana», en Actas de las I Jornadas de Metodología Aplicada de

47. LunENFELD, op. cit., pp. 52-54. 
JOSÉ ANTONIO JARA FUENTE

ENTRE EL CONFLICTO Y LA COOPERACIÓN: LA CIUDAD CASTELLANA Y LOS CORREGIDORES, PRAXIS DE UNA RELACIÓN POLÍTICA HASTA LA MONARQUÍA ISABELINA

las Ciencias Históricas. II. Historia Medieval. Santiago de Compostela, Universidad de Santiago de Compostela, 1975, pp. pp. 207-215.

Bermúdez Aznar, A.: «El asistente real en los concejos castellanos bajomedievales», en Actas del II Symposium de Historia de la Administración. Madrid, Instituto de Estudios Administrativos, 1971, pp. 225-251.

Bermúdez Aznar, A.: El corregidor en Castilla durante la Baja Edad Media (1348-1474). Murcia, Universidad de Murcia, 1974.

Bonachía Hernando, J. A.: «La justicia en los municipios castellanos bajomedievales», Edad Media. Revista de Historia, 1, 1998, pp. 145-182.

Cabrera Sánchez, M.: «Los corregidores de Córdoba en el siglo Xv», Meridies. Revista de Historia Medieval, 2, 1995, pp. 95-108.

Corral, J.: «Corregidores y alcaldes de Madrid. Estado de la cuestión», Anales del Instituto de Estudios Madrileños, 36, 1996, pp. 187-204.

Cuartas Rivero, M.: «Los corregidores de Asturias en la época de los Reyes Católicos (1474-1504)», Asturiensia Medievalia, 2, 1975, pp. 259-278.

Franco Silva, A. y Cruz Mariño, R.: «Juan Pacheco, privado de Enrique IV, y el oficio de corregidor de Jerez de La Frontera», En la España Medieval, 35, 2012, pp. 285-316.

García López, A.: «El corregidor y el conflicto ciudad-lugar en el Reino de Castilla (ss. XVI-XviI)», en Bernardo Ares, J. M. y González Beltrán, J. M. (coords.): La administración municipal en la Edad Moderna, actas de la $V$ reunión científica de la Asociación Española de Historia Moderna. Cádiz, Universidad de Cádiz, 2 vols., II, 1999, pp. 529-540.

González Alonso, B.: «La fórmula “Obedézcase pero no se cumpla” en el Derecho castellano de la Baja Edad Media», Anuario de Historia del Derecho Español, 50, 1980, pp. 469-488.

Jiménez AlCÁzAR, J. F.: «Corregidores y poder municipal: Lorca, 1475-1516», en Pradells Nadal, J. y Hinojosa Montalvo, J. R. (coords.): 1490: en el umbral de la modernidad: el Mediterráneo europeo y las ciudades en el tránsito de los siglos XV-XVI. Valencia, Generalitat Valenciana, 1994, 2 vols., II, pp. 87-96.

López Gómez, Ó.: «Claves del sistema de pacificación ciudadana desarrollado por los Reyes Católicos en Toledo (1475-1485)», En la España Medieval, 27, 2004, pp. 165-193.

López Villalba, J. M.: «El concejo imparte justicia: cotos de los oficiales locales a mediados del siglo Xv», Espacio, Tiempo y Forma. Serie III. Historia Medieval, 22, 2009, pp. 153-184.

LunEnfeld, M.: Keepers of the City. The Corregidores of Isabella I of Castile (1474-1504). Cambridge (Mass.), Cambridge University Press, 1987.

Martínez Carrillo, M. L.: «La implantación de los corregidores en el concejo murciano (1394-1402)», Miscelánea Medieval Murciana, 10, 1983, pp. 167-196.

Monsalvo Antón, J. M.: «El reclutamiento del personal político concejil. La designación de corregidores, alcaldes y alguaciles en un concejo del siglo XV», Studia Historica. Historia Medieval, 5, 1987, pp. 173-195. 
JOSÉ ANTONIO JARA FUENTE

ENTRE EL CONFLICTO Y LA COOPERACIÓN: LA CIUDAD CASTELLANA Y LOS CORREGIDORES, PRAXIS DE UNA RELACIÓN POLÍTICA HASTA LA MONARQUÍA ISABELINA

Narganes Quijano, F.: «Acerca de los primeros corregidores en Palencia (ss. XV-Xvi)», Publicaciones de la Institución Tello Téllez de Meneses, 64, 1993, pp. 597-610.

Palencia Herrejón, J. R.: Ciudad y oligarquía de Toledo a fines del medievo (1422-1522), tesis doctoral defendida en el Departamento de Historia Medieval de la Universidad Complutense de Madrid, 1999.

Quintanilla Raso, M. C.: «Estructuras y relaciones de poder en la tierra de Cuenca a fines de la Edad Media», en La Península Ibérica en la Era de los Descubrimientos (1391-1492), actas de las III Jornadas Hispano-Portuguesas de Historia Medieval 1991. Sevilla, Consejería de Cultura, 1997, 2 vols., I, pp. 707-736.

Robledo del Prado, M. L.: Formación y evolución de una oligarquía local: Los regidores de Lorca, tesis doctoral defendida en el Departamento de Historia Moderna de la Universidad Complutense de Madrid, enero de 1995, edición facsímil, Madrid, Universidad Complutense de Madrid, 2002.

Rufo Ysern, P.: «Extensión del régimen de corregidores en Andalucía en los primeros años del reinado de los Reyes Católicos», en Las ciudades andaluzas (siglos XIII-XVI), actas del VI Coloquio Internacional de Historia Medieval de Andalucía. Málaga, Universidad de Málaga, 1991, pp. 55-75.

Ruiz Povedano, J. M.: «Poder, oligarquía y parcialidades en Alcalá la Real: el asesinato del corregidor Bartolomé de Santa Cruz (1492)», Historia. Instituciones. Documentos, 29, 2002, pp. 397-427.

Sánchez Benito, J. M.: «Nobleza territorial y política ciudadana en el siglo xv (los concejos del área del Tajo)», Espacio, Tiempo y Forma. Serie III. Historia Medieval, 27, 2014, pp. 463-502.

YвÁÑEZ WorboYs, P.: «Los corregidores malagueños (1517-1556)», en Actas de la V reunión cientifica de la Asociación Española de Historia Moderna, Cádiz, 1998. Cádiz, Universidad de Cádiz, 1999, 2 vols. II, pp. 179-190. 
